\title{
The Potential Anticancer Activity of 5-Fluorouracil Loaded in Cellulose Fibers Isolated from Rice Straw
}

This article was published in the following Dove Press journal:

International Journal of Nanomedicine

\author{
Mostafa Yusefi, (D) Kamyar \\ Shameli, (ID) Hossein \\ Jahangirian, (D) Sin-Yeang \\ Teow, (D) Hiroshi Umakoshi, \\ Bahram Saleh, (D) Roshanak \\ Rafiee-Moghaddam, (D) Thomas \\ J Webster (1)
}

'Malaysia-Japan International Institute of Technology, Universiti Teknologi Malaysia, Kuala Lumpur 54I00, Malaysia;

${ }^{2}$ Department of Chemical Engineering, College of Engineering, Northeastern University, Boston, MA 02II5, USA; ${ }^{3}$ Department of Medical Sciences, School of Healthcare and Medical Sciences, Sunway University, Selangor Darul Ehsan 47500, Malaysia; ${ }^{4}$ Bio-Inspired Chemical Engineering Laboratory, Division of Chemical Engineering, Graduate School of Engineering Science, Osaka University, Osaka 560-853I, Japan

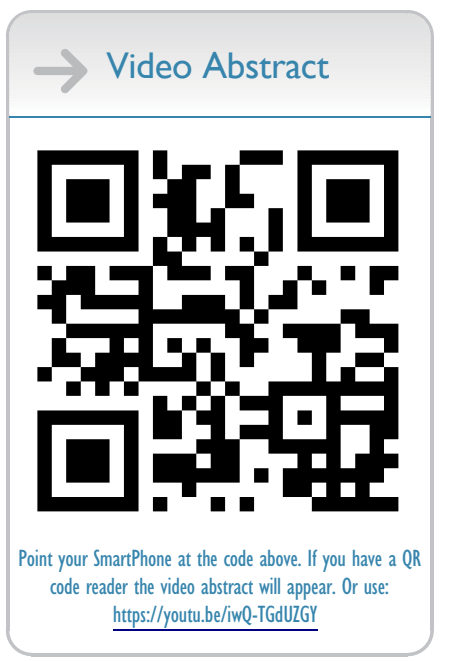

Correspondence: Kamyar Shameli; Hossein Jahangirian

Tel +60173443492; + I 6I78608429 Email kamyarshameli@gmail.com; kamran.jahangirian@gmail.com
Introduction: Green-based materials have been increasingly studied to circumvent offtarget cytotoxicity and other side-effects from conventional chemotherapy.

Materials and Methods: Here, cellulose fibers (CF) were isolated from rice straw (RS) waste by using an eco-friendly alkali treatment. The CF network served as an anticancer drug carrier for 5-fluorouracil (5-FU). The physicochemical and thermal properties of CF, pure 5-FU drug, and the 5-FU-loaded CF (CF/5-FU) samples were evaluated. The samples were assessed for in vitro cytotoxicity assays using human colorectal cancer (HCT116) and normal (CCD112) cell lines, along with human nasopharyngeal cancer (HONE-1) and normal (NP 460) cell lines after 72-hours of treatment.

Results: XRD and FTIR revealed the successful alkali treatment of RS to isolate CF with high purity and crystallinity. Compared to RS, the alkali-treated CF showed an almost fourfold increase in surface area and zeta potential of up to $-33.61 \mathrm{mV}$. SEM images illustrated the CF network with a rod-shaped structure and comprised of ordered aggregated cellulose. TGA results proved that the thermal stability of 5-FU increased within the drug carrier. Based on UV-spectroscopy measurements for 5-FU loading into $\mathrm{CF}$, drug loading encapsulation efficiency was estimated to be $83 \pm 0.8 \%$. The release media at $\mathrm{pH} 7.4$ and $\mathrm{pH}$ 1.2 showed a maximum drug release of $79 \%$ and $46 \%$, respectively, over 24 hours. In cytotoxicity assays, CF showed almost no damage, while pure 5-FU killed most of the both normal and cancer cells. Impressively, the drug-loaded sample of CF/5-FU at a $250 \mu \mathrm{g} /$ $\mathrm{mL}$ concentration demonstrated a $58 \%$ inhibition against colorectal cancer cells, but only a $23 \%$ inhibition against normal colorectal cells. Further, a $62.50 \mu \mathrm{g} / \mathrm{mL}$ concentration of $\mathrm{CF} / 5 \mathrm{FU}$ eliminated $71 \%$ and $39 \%$ of nasopharyngeal carcinoma and normal nasopharyngeal cells, respectively.

Discussion: This study, therefore, showed the strong potential anticancer activity of the novel $\mathrm{CF} / 5-\mathrm{FU}$ formulations, warranting their further investigation.

Keywords: rice straw, cellulose fibers, 5-fluorouracil, drug delivery, cytotoxicity assays, cancer treatment

\section{Introduction}

Over the years, researchers have been continuously interested in using agro-waste for producing eco-friendly materials to decrease environmental issues, including toxicity and a reduction in landfill space. ${ }^{1,2}$ For example, burning rice straw (RS), which represents the second highest agro-waste, causes health risks from air pollution and effects organic matter with large nutrient losses. ${ }^{3}$ It should be noted that similar to other plant-based resources, RS contains a high ratio of cellulose fibers (CF) $\left(\mathrm{C}_{6} \mathrm{H}_{10} \mathrm{O}_{5}\right) .{ }^{4} \mathrm{CF}$ as one of the unique and abundant organic polymers on earth, is becoming more and more popular for different applications. It contains a high

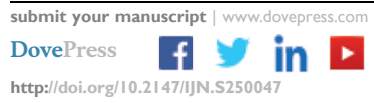


number of glucose, which is linked by $\beta$-1,4-glycosidic in a linear chain format. Therefore, it possesses remarkable structural advantages, including high porosity, pore interconnectivity, large surface-to-volume ratios, low density, and hydrophilicity with good physicochemical properties. ${ }^{5}$

Among the various methods to isolate $\mathrm{CF}$, alkaline treatments are known as a facile and economical approach to remove lipids, lignin, hemicellulose, and pectin from plant-based materials. This treatment removes an amorphous region, while the crystal region is protected to obtain CF with high crystallinity and purity. Therefore, the crystallization of CF occurs at the external layer by the establishment of a glucan chain through the van der Waals and H-bonding forces. ${ }^{6} \mathrm{CF}$ is also one of the bioresource polysaccharides, which has been evaluated as a 5-FU carrier due to its ability to target cancer cells through the enhanced permeability and retention effect (EPR). ${ }^{7}$ Compared to commercial $\mathrm{CF}$, treated $\mathrm{CF}$ can show higher thermal stability, ${ }^{8}$ while its purity and crystallinity may be optimized by removing a sufficient amount of lignin and hemicellulose, and also changing treatment duration and concentration of an alkaline solution. ${ }^{9}$ Therefore, alkali-treated CF can provide various advantages, such as easily reducing fiber size to the micro or nanoscale as well as gaining adjustability and reproducibility through the modification of the alkaline solution and treatment time. ${ }^{10}$ Further, the alkali-treated CF can be dispersed well in water to obtain a uniform biopolymer for biomedical applications. ${ }^{10}$ However, it was stated that some properties (such as tensile strength) were similar between the commercial and alkali-treated $\mathrm{CF}^{9}$ Above all, as an environmental-friendly technique, using biowaste materials (such as RS) can be beneficial for producing $\mathrm{CF}$ with better physicochemical properties than commercial CF.

Cancer statistics from over 185 countries have demonstrated 18.1 million new cancer cases from 36 different types of cancers in just 2018 alone. ${ }^{11}$ Colorectal cancer (CRC) is one of the most diagnosed malignant diseases globally leading to the death of more than 600,000 patients every year. ${ }^{12} \mathrm{CRC}$ is attributed to colon cancer, rectal cancer, and bowel cancer and is mostly developed inside polyps (adenoma) and formed within the bowel wall. ${ }^{13}$ Nasopharyngeal carcinoma (NPC) is an Epstein-Barr virus (EBV)-related head and neck cancer. ${ }^{14}$ NPC has been mostly reported in South Asia, North Africa, Southern China, and in countries of the Arctic. ${ }^{15}$
Different sorts of cancer and solid tumor formation are typically due to the disordered function inside cells as their chromosomes can be lost or not duplicated in such dysfunctional rearrangements. ${ }^{16}$ Conventional cancer treatments (such as chemotherapy, radiation, and surgery) present significant drawbacks to human health. ${ }^{17}$ Compared with such pure conventional anticancer drugs, nanosized conjugates may provide for better anticancer properties and safer drug treatments through prolonged circulation and targeted treatment. ${ }^{18}$ Therefore, researchers have designed new-targeted drug delivery systems with plant-based medicines ${ }^{19}$ and nanomedicines of low price, high efficiency, and safety for decreasing the side-effects from conventional cancer treatments. Such nano-drug delivery systems may act as suitable platforms to develop efficient drug delivery processes.

In this manner, different polysaccharides (including chitin, ${ }^{20}$ cellulose, ${ }^{21}$ and their by-products) have been investigated as novel polymer-anticancer drug conjugates, owing to the enzymatic degradation of the most polysaccharides through colonic microbial agents. ${ }^{22}$ Further, polysaccharides can be used as polymeric nanoparticles (NPs) derived from nature with sizes between $10 \mathrm{~nm}$ and $1 \mu \mathrm{m} .{ }^{23}$ Polymeric NPs have recently become popular for researchers in drug delivery systems, due to their optimal physicochemical and biological features, and the ability for delivering drugs to different organs. ${ }^{23}$

Based on their preparation technique used, polymeric NPs may be classified into two categories: i) nanospheres that contain a solid support system or as a platform to be loaded with a dispersed drug or ii) nanocapsules that contain embedded drug cavities as the polymeric substance covers the cavity. ${ }^{24}$ Drug delivery systems can influence the microenvironment of tumors, which is leaky with a higher sensitivity to macromolecules compared with normal cells. ${ }^{25}$ Further, the lymphatic system of tumors is mostly inefficient and even blocked, causing preservation needs in the tumor interstitial fluid. ${ }^{25}$ Polymeric NPs can, thus, accumulate 100 times greater in cancer cells compared to normal cells. ${ }^{25}$

Drug accumulation in the interstitial fluid phase of tumors occurs due to NP extravasation from the vasculature of tumors, leading to the EPR effect. ${ }^{26}$ The amount of NP extravasation relies on the dimension of transendothelial and channels via inter-endothelial cell gaps with the range of $400-600 \mathrm{~nm}^{27}$ It has been reported that NPs below $200 \mathrm{~nm}$ could be appropriately extravasated from the tumor microvasculature. ${ }^{28}$ Polymeric NPs (such as 
cellulose and chitosan) have been commonly applied in topical drug delivery systems for controlled dosing and targeted drug delivery. For instance, as a platform of chitosan, nanocellulose and sodium alginate could successfully control the release behavior of Levamisole hydrochloride and 5-fluorouracil (5-FU) drugs to provide a high antiproliferation behavior against HT29 colon cancer cells with low side-effects. ${ }^{29}$

Such NPs can easily encapsulate different drugs (including Bevacizumab, Camptosar, Capecitabine, Cetuximab, and 5-FU) approved for the chemotherapeutic treatment of different cancers (such as CRC, breast cancer, and esophageal cancer) ${ }^{30}$ to improve cancer treatment. Further, for over six decades, the 5-FUbased chemotherapy treatment has been widely applied for both adjuvant and advanced therapy of different cancers, including CRC and NPC. ${ }^{15,31}$ This therapy can destroy the function of the thymidylate synthetase protein enzyme in CRC treatment. ${ }^{31}$ 5-FU may also inhibit RNA and DNA damage causing cancer cell inhabitation. ${ }^{32}$ It has been shown to extend cancer cell survival for more than 6 months under the best conditions of metastatic cancer. ${ }^{33}$

However, side-effects from 5-FU-based chemotherapy may cause different issues, including diarrhea, stomatitis, and gastrointestinal mucosal injury. ${ }^{34}$ The toxicity of 5-FU is potentially through its long chemotherapy period and nonspecific protective mechanisms over normal healthy cells. ${ }^{35}$ These disadvantages of 5-FU in cancer treatment can be decreased through minimizing drug dosage used in a targeted drug delivery platform. ${ }^{36}$ 5-FU, therefore, has been used in different platforms or solid supports, such as chitosan ${ }^{17}$ and cellulose. ${ }^{37}$ In a study, acid hydrolyzed crystal nanocellulose was obtained successfully from rubber wood for hesperidin (hydrophobic drug) delivery; however, cytotoxicity assays were not considered. ${ }^{37}$ In a recent survey, a lignosulfonate (LS)/mercerized cotton composite was fabricated and caused an acceptable elimination of human CRC cells HCT116, human breast cancer cells MCF-7, and human liver cancer cells HepG2. However, cytotoxicity assays on the fabricated material against normal healthy cells were not considered. ${ }^{38}$ A novel cellulose-based 5-FU was synthesized and analyzed for the elimination of human breast cancer (MCF-7) cells, although it was not analyzed for normal cells. ${ }^{39}$

Albeit, there has been no report for loading anticancer drug 5-FU in CF extracted from RS for nasopharyngeal and colon cancer treatments, for which this study conducted. Specifically, in this work, CF was obtained by alkaline delignification and bleaching of RS. Here, $\mathrm{CF}$ demonstrated significant promise as a 5-FU carrier for CRC and NPC treatment. Successful CF isolation from RS was provided through $\mathrm{X}$-ray powder diffraction (XRD), Fourier-transform infrared spectroscopy (FTIR), scanning electron microscopy (SEM) and BrunauerEmmett-Teller (BET) techniques. 5-FU conjugation into $\mathrm{CF}$ was accomplished in which the drug absorbance and release were, respectively, evaluated through ultraviolet-visible (UV) spectroscopy. The drug-loaded CF was analyzed by a zeta potential analyzer, FTIR, and thermogravimetric analysis (TGA). MTS in vitro cytotoxicity assays evaluated the cytotoxicity of $\mathrm{CF}$ and the anticancer potential of 5-FU as well as the drug-loaded CF against CCD112 normal colorectal and HCT116 colorectal cancer cells as well as NP 460 normal nasopharyngeal and HONE-1 nasopharyngeal cancer cell lines at eight different concentrations.

\section{Materials and Methods Materials}

RS was obtained from the Malaysian Agricultural Research and Development Institute (MARDI). All chemicals were of analytical grade as purchased from Sigma-Aldrich (St Louis, MO, USA) without further purification. For the bleaching process and $\mathrm{CF}$ isolation from RS, potassium hydroxide $(\mathrm{KOH}, 85 \%$, EM Science), sodium chlorite $\left(\mathrm{NaClO}_{2}, 80 \%\right.$, Fluka), and acetic acid glacial $\left(\mathrm{CH}_{3} \mathrm{COOH}\right)$ were used, respectively. The aqueous solutions were freshly prepared and distilled water with a specific conductivity of less than $1 \mu$ $\mathrm{ohm} / \mathrm{cm}$ was used. All glassware used in this work were cleaned with $\mathrm{HNO}_{3} / \mathrm{HCl}(3: 1, \mathrm{v} / \mathrm{v})$ and double deionized water followed by a drying process. 5-fluorouracil, 99\%, 5-Fluoro-2,4 $(1 \mathrm{H}, 3 \mathrm{H})$-pyrimidinedione (ACD CODE MFC D00006018) with a molecular weight of 130.08 $\mathrm{g} / \mathrm{mol}$ was purchased from ACROS ORGANICS, part of Thermo Fisher Scientific, New Jersey, USA.

\section{Cellulose Fiber Isolation from Rice Straw} Similar to different bio-fiber resources, CF isolation from RS was carried out through removing and bleaching the unwanted components, such as lipid and lignin. RS was washed several times with tap water to remove the dirt and dust, followed by seven days of air-drying at ambient temperatures. Dried RS was then ground and 
milled through a $55 \mu$-mesh screen. To obtain dewaxed rice straw (DRS) with free-lipids, a $30 \mathrm{~g}$ RS powder was initially dewaxed to dissolve the oils, wax, lipids, and pigments in a $2: 1, \mathrm{v} / \mathrm{v}$ toluene/ethanol $(450 \mathrm{~mL})$ aqueous solution in a soxhlet instrument for 12 hours at $70^{\circ} \mathrm{C}$ using a silicon oil bath. The pasty dark brown color sample was sonicated by ultrasonic frequency at 37 $\mathrm{kHz}$ (Elmasonic S) and then washed with distilled water three times with the extra liquid decanted using a lab suction filtration unit equipped with Whatman filter-paper followed by a drying process in a $60^{\circ} \mathrm{C}$ oven for 24 hours.

To remove lignin, DRS powder was mixed with a $1000 \mathrm{~mL}$ aqueous solution of sodium chloride (1.4\%) by adding drops of acetic acid (which turned the $\mathrm{pH}$ to $3.0-4.0$ ) at $70^{\circ} \mathrm{C}$ with gentle magnetic stirring for 5 hours, followed by washing and decanting of the extra liquid several times to obtain a light yellowish solid sample. After that, the sample was leached by applying a $600 \mathrm{~mL}$ aqueous solution of $\mathrm{KOH}(5 \%)$ at the ambient temperature for 12 hours, followed by pouring (10 fold) ice cubes immediately into the solution. The aqueous sample was centrifuged at $12,000 \mathrm{rpm}$ and dried by a freeze-dryer apparatus (FreeZone 1.0 L Benchtop
Freeze Dry System) to finally obtain a white pulpy fiber sample, which was named $\mathrm{CF}$. The schematic process of this study is shown in Figure 1.

\section{Characterization of Cellulose Fiber Isolation from Rice Straw}

XRD (Philips, X'pert, $\mathrm{Cu} \mathrm{Ka}$ ) at $2 \theta$ over the range of $10-90^{\circ}$ was used to evaluate the crystalline phases of the samples. The samples were compressed between two smooth glass films. XRD was performed under ambient conditions upon dispersion of 2 theta angles of $5^{\circ}-40^{\circ}$ with a step size of $0.02^{\circ}$ and a scanning rate of $2 \mathrm{~s} /$ step utilizing Ni-filtered $\mathrm{Cu}$ $\mathrm{K}$ radiation (=1.5406 Angstroms), an operating voltage of 45 $\mathrm{kV}$, and a filament current of $40 \mathrm{~mA}$. Scanning electron microscopy (SEM) images were taken with an Electro-Scan SEM instrument (model JSM 7600 F SEM) attached to an energy dispersion X-ray spectroscopy spectrometer (EDX) to study the elemental compositions. Low-acceleration voltage $(10 \mathrm{kV})$ was used to prevent the degradation of CF and DRS. The pressure in the chamber was 5 torr, the condenser lens setting was 40\%, and magnification was at 500-1000 times the original. For BET analysis, the samples were first degassed at $35^{\circ} \mathrm{C}$ under vacuum for 24 hours and then through a surface area and porosity analyzer (ASAP 2020,

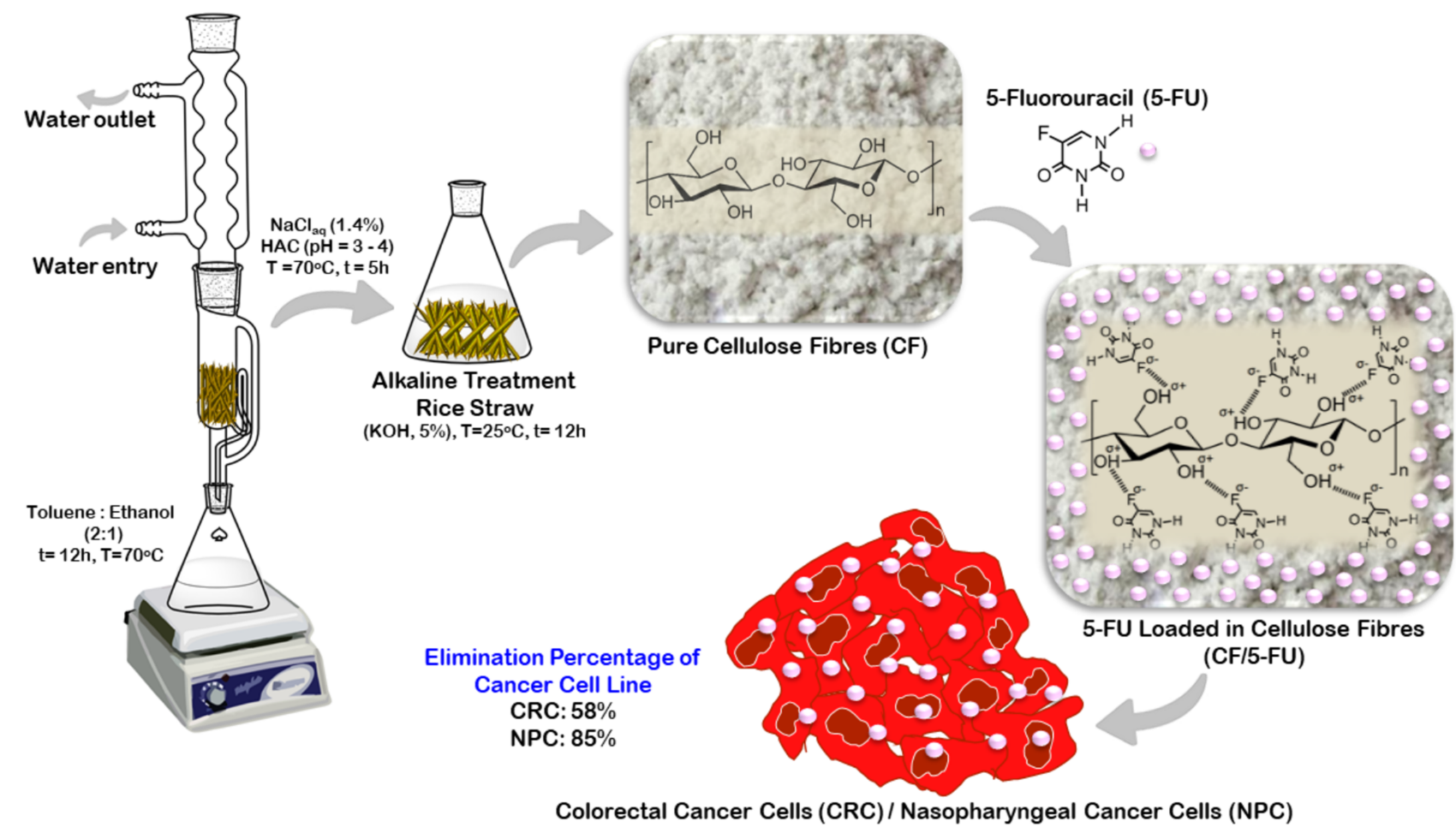

Figure I A schematic process for cellulose fiber (CF) isolation from rice straw (RS), also showing that CF served as a drug carrier for 5-fluorouracil (5-FU), which was assessed using MTS in vitro cytotoxicity assays with human colorectal and nasopharyngeal cell lines. 
Micromeritics, USA), the nitrogen adsorption-desorption isotherms of the degassed sample were evaluated at 77 $\mathrm{K}$. The BET calculation was conducted as a relative pressure range from 0.06 to 0.20 . The Barrett-Joyner-Halenda (BJH) method, with the volume absorbed under a relative pressure $(\mathrm{P} / \mathrm{Po}=0.98)$, was employed to measure pore size distribution as total pore capacity. The chemical and super-molecular structural analyses were determined by FTIR spectroscopy (Thermo Nicolet, USA) under ambient conditions. First, the sample was crushed with $\mathrm{KBr}$ at a ratio of $1: 100 \mathrm{w} / \mathrm{w}$ and compressed into a transparent pellet. The spectra was evaluated under transmittance mode in a range between 4000 and $400 \mathrm{~cm}^{-1}$ with a $4 \mathrm{~cm}^{-1}$ resolution and an accumulation of 128 scans. The average zeta potential values were measured by Anton Paar instruments (Litesizer ${ }^{\mathrm{TM}} 500$ and SurPASS ${ }^{\mathrm{TM}} 3$ ) as the samples were diluted with distilled water to make a concentration of $5 \% \mathrm{v} / \mathrm{v}$. Thermal analysis was carried out by TGA employing a TGA (STA F3 Jupiter) Q50 V20 at a $10^{\circ} \mathrm{C} / \mathrm{min}$ heating rate under a nitrogen atmosphere $\left(10 \mathrm{~mL} \mathrm{~min}^{-1}\right)$. The analysis was done at a temperature from $10^{\circ} \mathrm{C}$ to $800^{\circ} \mathrm{C}$.

\section{5-FU Loading Study}

A $250 \mathrm{~mL}$ solution of distilled water containing 5-FU and $\mathrm{CF}$ and at a weight ratio of 1:3.5 was stirred in stoppered bottles at $300 \mathrm{rpm}$ for 14 hours. The drug-loaded sample was washed with distilled water and centrifuged using a Tabletop Centrifuge (Kubota, Model: 2420) with a $15 \mathrm{~mL}$ centrifuge tube at $4000 \mathrm{rpm}$ for 8 minutes. After that, the supernatant was analyzed using UV-vis spectrophotometry with a UV-visible spectrophotometer (UV-1600, Shimadzu, Japan) at $266 \mathrm{~nm}$ to determine the amount of unentrapped drug. After centrifugation, the sample was collected and dried in an oven at $45^{\circ} \mathrm{C}$ and named $\mathrm{CF} / 5-\mathrm{FU}$. The amount of drug-loaded in $\mathrm{CF} / 5-\mathrm{FU}$ was determined by using a calibration curve generated from known concentrations of 5-FU and was used to calculate the loading capacity (LC)\% and the drug encapsulation efficiency (EE)\% according to Equations (1 and 2), respectively.

$$
\begin{aligned}
& \mathrm{LC} \%= \frac{\left(\begin{array}{l}
\text { Initial drug amount } \\
\text { in formulation }(\mathrm{mg})
\end{array}-\begin{array}{c}
\text { Unentrapped } \\
\text { drug }(\mathrm{mg})
\end{array}\right)}{\begin{array}{l}
\text { Total weight of } \\
\text { drug in } \mathrm{CF} / 5 \mathrm{FU}
\end{array}} \\
& \times 100 \% \quad
\end{aligned}
$$

$$
\begin{aligned}
& \mathrm{EE} \%= \frac{\left(\begin{array}{l}
\text { Initial drug amount } \\
\text { in formulation }(\mathrm{mg})
\end{array}-\begin{array}{l}
\text { Unentrapped } \\
\text { drug }(\mathrm{mg})
\end{array}\right)}{\begin{array}{l}
\text { Initial drug amount } \\
\text { in formulation }(\mathrm{mg})
\end{array}} \\
& \times 100 \% \quad
\end{aligned}
$$

\section{In Vitro Drug Release Studies}

The release of 5-FU from $\mathrm{CF}$ as an anticancer drug carrier was studied by using a $5 \mathrm{~mL}$ dialysis bag (molecular weight cut-off between 12,000 and 14,000 Da). Before the experiment, the bag was soaked for 12 hours in the release medium of simulated colorectal fluid (phosphate-buffered saline (PBS) at $\mathrm{pH}$ 7.4). Then, the solution mixture of $5 \mathrm{mg}$ of $\mathrm{CF} / 5-\mathrm{FU}$ and $2 \mathrm{~mL}$ of the release medium was suspended in a $5 \mathrm{~mL}$ dialysis bag with the two ends tied. The bag was completely immersed into a $40 \mathrm{~mL}$ of the release media maintained under constant stirring of $100 \mathrm{rpm}$ at $37^{\circ} \mathrm{C}$ in two different stoppered bottles. A $1 \mathrm{~mL}$ aliquot was withdrawn from the system at the selected time and then it was immediately replaced with the same volume of the fresh media. The collected sample at a different time was characterized by UV-vis spectrophotometry at $266 \mathrm{~nm}$. The same study was performed in a hydrochloric acid (HCl) buffer at $\mathrm{pH} 1.2$ for the simulated release of the drug in the stomach and a comparison of the differences in the drug release profiles estimated from the $\mathrm{CF}$ in media at different $\mathrm{pH}$ values. The results obtained from the media with two different $\mathrm{pH}$ values were calculated by the following equation and then compared:

$$
\text { Drug release }(\%)=\frac{\begin{array}{l}
\text { Amount of drug } \\
\text { release time }{ }^{\prime} t^{\prime}
\end{array}}{\text { Amount of drug }} \times 100 \%
$$

The release experiment was continued until the absorbance of the media remained constant. All experiments were carried out in triplicate.

\section{Cell Lines and Reagents}

Human HCT116 CRC cells (ATCC CCL-247) and CCD112 normal colorectal cells (ATCC CRL-1541) were purchased from ATCC and cultured according to the ATCC's recommendation. The NP 460 nasopharyngeal normal cell line ${ }^{40}$ and the HONE-1 cancer cell line derived from a nasopharyngeal carcinoma ${ }^{41,42}$ was a kind gift from Dr. Alan Khoo Soo-Beng from the Institute for Medical Research, Malaysia. Cell authentication for HONE-1 and 
NP460 was performed by short tandem repeat (STR) profiling. The results showed that both cell lines were authentic by showing a 93.75 and $100 \%$ match with the reference cell lines, HONE-1 (CVCL_8706) and NP460 (CVCL_X205), respectively, from the ExPASy database (Table S1). The match analysis was performed using the cellosaurus STR similarity search tool CLASTR 1.4.3 on the ExPASy website (https://web.expasy.org/cellosaurusstr-search/). The cell lines were maintained in Dulbecco's Modified Eagle's medium (DMEM) supplemented with $10 \%$ fetal bovine serum (FBS) (Gibco) and 1\% penicillin/streptomycin (Gibco). All cell lines used for cytotoxicity experiments were less than a passage number of 10 .

\section{MTS In Vitro Cytotoxicity Assays}

To determine the cellular killing effect from 5-FU, CF/ 5-FU, and CF samples, cytotoxicity assays were performed using a CellTiter 96 Aqueous One Solution (MTS reagent) (\#G3582, Promega) according to the manufacturer's instructions with a slight modification as previously described. ${ }^{43-45}$ Briefly, 5000 HCT116 and CCD112 cells per well (100 $\mu \mathrm{L} /$ well) were seeded onto a 96-well plate and incubated overnight at $37^{\circ} \mathrm{C}$ in a $5 \%$ $\mathrm{CO}_{2}, 95 \%$ humidified incubator. The next day, 2-fold serially diluted samples at concentrations of $0,7.81$, $15.62,31.25,62.53,125,250$ and $500 \mu \mathrm{g} / \mathrm{mL}(100 \mu \mathrm{L} /$ well) were added into the wells and the plate was incubated for 72 hours at $37^{\circ} \mathrm{C}$ in a $5 \% \mathrm{CO}_{2}$ incubator. Then, $20 \mu \mathrm{L}$ of the MTS reagent per well were added into the plate and incubated for an additional 3 hours at $37^{\circ} \mathrm{C}$ in a $5 \% \mathrm{CO}_{2}$ incubator. The optical density (OD) was then measured at $490 \mathrm{~nm}$ using a multimode microplate reader (Tecan). The dose-response graph was plotted by calculating the percent cell viability using equation (4):

$$
\% \text { Cell viability }=\frac{\text { OD of sample well }(\text { mean })}{\text { OD of control well }(\text { mean })} \times 100 \%
$$

In addition, the inhibitory concentration causing $50 \%$ growth inhibition $\left(\mathrm{IC}_{50}\right)$ was determined using an online calculator (https://www.aatbio.com/tools/ic50-calculator) as previously described. ${ }^{43,44}$

\section{Statistical Analysis}

Independent experiments were performed three times and the data are expressed as the mean \pm standard deviation for all triplicates within an individual experiment. Data were analyzed with a Student's $t$-test using SPSS version 26.0 where $\mathrm{p}<0.05$ was considered significant.

\section{Results and Discussion}

\section{Reaction}

The brown color of RS was gradually removed to finally obtain white CF. A 35\% CF yield was achieved from RS which was almost similar to the results from different studies. $^{46,47}$ The step-by-step process of CF isolation was proved by XRD and FTIR characterization.

\section{X-Ray Powder Diffraction (XRD)}

The XRD evaluation of RS, DRS, and CF is shown in Figure $2 \mathrm{~A}-\mathrm{C}$, respectively. As can be observed from the figure, all of the samples indicated a similar XRD pattern, showing that the chemical treatment did not damage the cellulose structure. The samples displayed peaks at approximately $2 \theta=14.6^{\circ}, 16.5^{\circ}$, and $22.4^{\circ}$, in agreement with the normal cellulose-I structure. ${ }^{48}$ The cellulose crystals had, 110, 200, and 004 planes. ${ }^{49}$ The intensity of the peaks gradually increased by the treatments as unwanted components (such as lignin and lipids) were gradually removed from RS by the treatments to isolate $\mathrm{CF}$ with high purity. The main elements in the amorphous region of RS were lipid, hemicellulose, and lignin, which were peeled off and hydrolyzed during the alkaline treatment. Therefore, the amorphous region was gradually removed

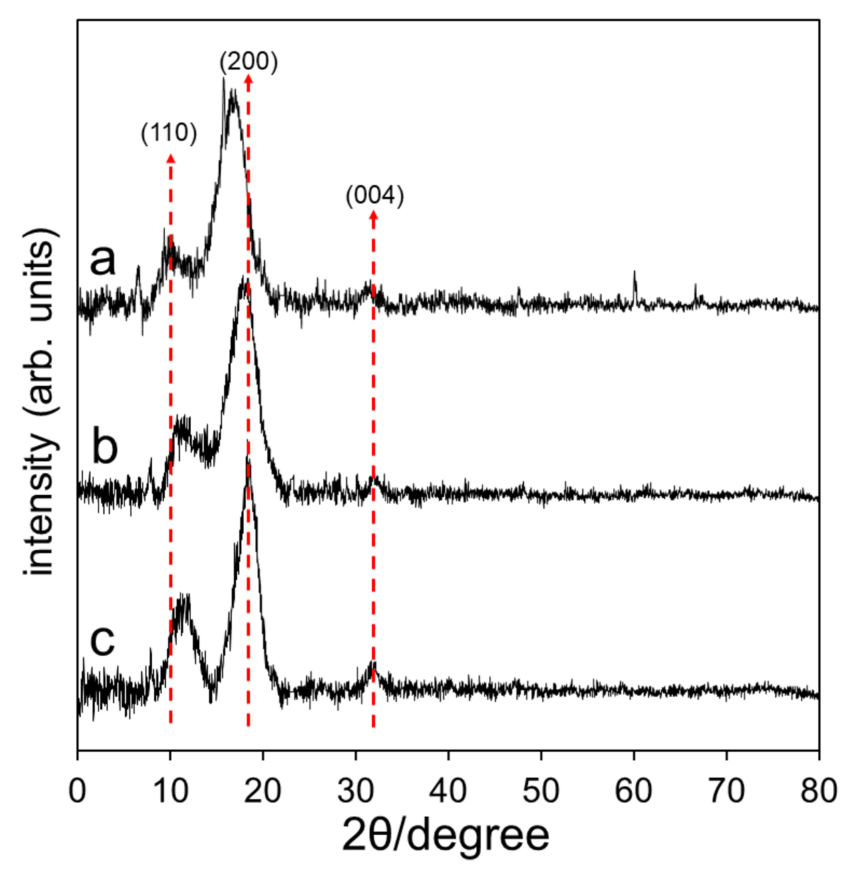

Figure 2 X-ray powder diffraction of (A) RS, (B) DRS and (C) CF. 
after each treatment while the crystal region was protected. Similar to a different report, ${ }^{47}$ the treatment possibly improved organization and alignment as well as crystal interfaces for the obtained materials.

\section{Scanning Electron Microscope (SEM) and Energy Dispersive X-Ray Analyses (EDX)} SEM of DRS (Figure 3A and B), CF (Figure 3C and D), and $\mathrm{CF} / 5-\mathrm{FU}$ (Figure 3E) were respectively evaluated. SEM allowed for good morphological visualization of the swelled materials. Therefore, the SEM image showed the size of CF after swelling in the aqueous solution. It can be seen clearly in the images that $\mathrm{CF}$ was smaller with a better-organized structure compared to DRS. This was due to removing hemicellulose and lignin by dewaxing and delignification treatments. Figure $3 \mathrm{C}$ and $\mathrm{D}$ show that CF was mostly rod-shaped and was comprised of ordered aggregated cellulosic fibrils with disordered structures. In nature, each fiber contains up to a hundred of nano/microfibers coalesced together into a cellulosic structure.
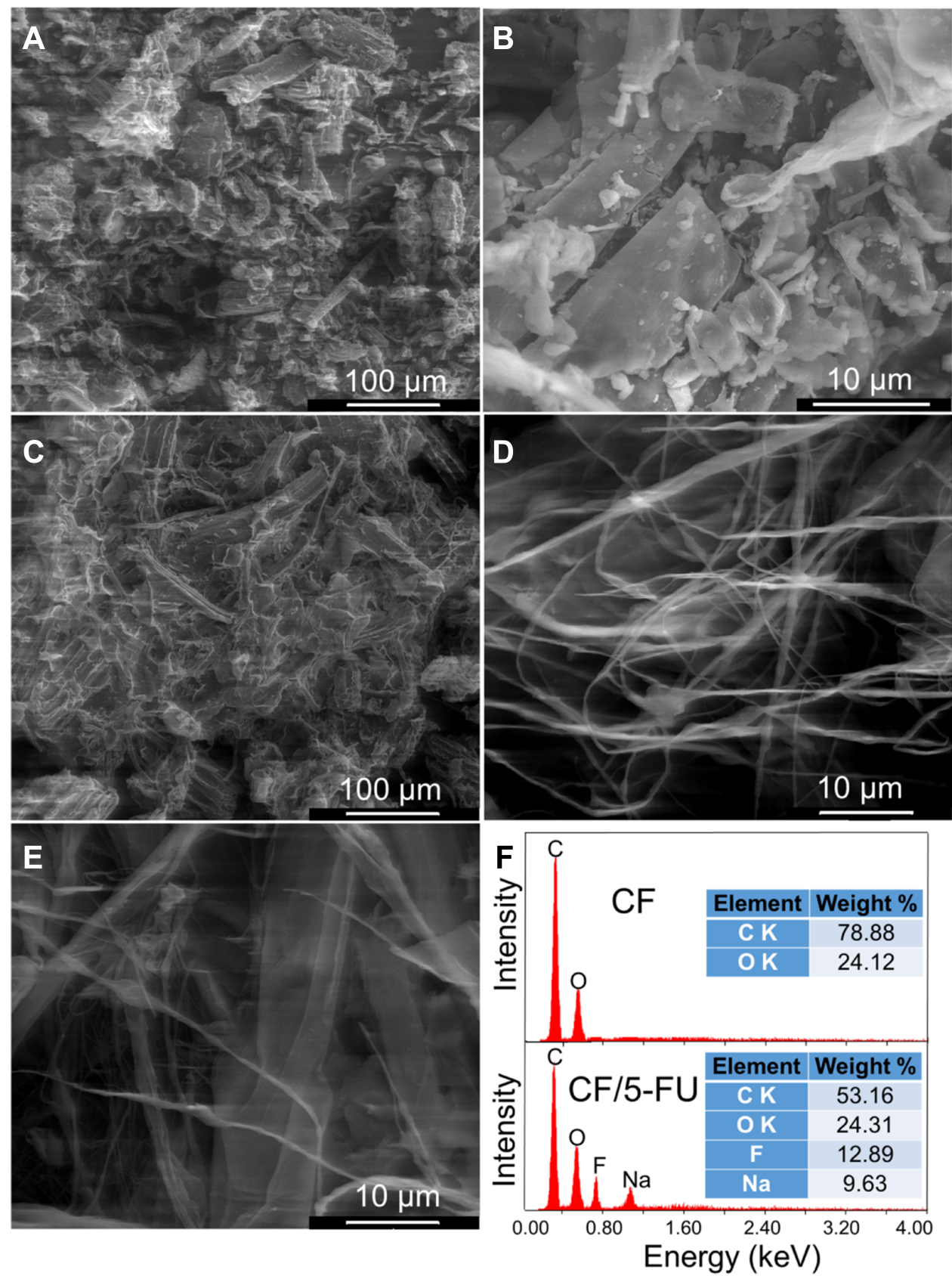

Figure 3 Scanning electron microscope images of (A and B) DRS, (C and D) CF, and (E) CF/5-FU and (F) energy dispersive X-ray analysis of CF and CF/5-FU. 
Obviously, CF compared to DRS was not only more mesoporous but it also provided for a better uniform pore structure. From Figure 3D, some pores can be seen on the surface of the $\mathrm{CF}$, allowing for water and also hydrophilic drug penetration into the fiber. The size of CF (Figure 3D) and CF/5-FU (Figure 3E) was similar, possibly because of the highly water-soluble 5-FU entrapped well within the porous network of $\mathrm{CF}$, therefore, it did not change the morphological properties of the drugloaded sample. Similarly, in a different study, ${ }^{39}$ SEM images of the cellulose-based 5-FU carrier indicated a smooth and uniform morphology, representing the successful encapsulation of the drug.

Based on EDX data (Figure 3F), the CF network contained $75.88 \mathrm{wt} \%$ carbon and $24.12 \mathrm{wt}$ \% oxygen. The RS treatment dissolved silica into aqueous ions and was subsequently replaced by carbon, providing an improvement in crystallinity and surface area of the isolated $\mathrm{CF}^{50}$ Further results indicated that $\mathrm{CF} / 5-\mathrm{FU}$ comprised 53.26 wt.\% carbon, 24.31 wt.\% oxygen, 12.81 wt.\% fluorine (F), and a negligible wt.\% ratio of $\mathrm{Na}$. Therefore, EDX results of $\mathrm{CF} / 5-\mathrm{FU}$ confirmed the effective drug loading into $\mathrm{CF}$ via presenting an adequate amount of fluorine (F) from $5-\mathrm{FU}$ in the drug carrier.

\section{Brunauer-Emmett-Teller (BET) Measurements}

Figure $4 \mathrm{~A}$ and $\mathrm{B}$ show the BET evaluation of DRS and CF. The nitrogen adsorption-desorption approach at $77 \mathrm{~K}$ was used to measure the surface area and pore volume of DRS and CF with nearly reversible loops and type II isotherms, based on the IUPAC classification. As can be seen from Figure 4A, the BET surface areas of DRS and CF were 4.59 and $18.34 \mathrm{~m}^{2} / \mathrm{g}$, respectively. Compared to DRS, CF has an approximately four-time higher surface area with higher porosity. Figure 4A shows the adsorption-desorption of the samples. Based on the Le-Chatelier principle, the value of stress between the adsorption and desorption was evaluated considering the orientation changes during equilibrium by the number of the molecular alterations.

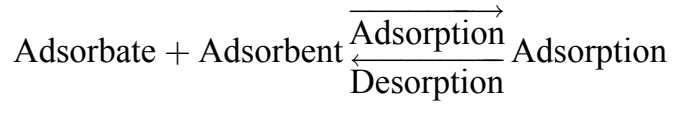

The Langmuir adsorption isotherm can be presumed as a dynamic equilibrium that occurs between free and adsorbed gaseous molecules. The BJH cumulative pore volume was calculated from the adsorption branch of each isotherm. The pore volume was almost four-times higher for $\mathrm{CF}$ $\left(0.022 \mathrm{~cm}^{3} / \mathrm{g}\right)$ than DRS $\left(0.006 \mathrm{~cm}^{3} / \mathrm{g}\right)$. This could be due to the hydrogen bonds between CF components. During the alkaline treatment on DRS, the removal of silica and lignin was the key factor to decrease the amorphous region and obtain CF with a proper crystal region, causing a high surface area. ${ }^{51}$ According to Figure 4B, CF showed almost a twofold increase in the average pore diameter than DRS. Besides, the pore diameter for DRS and CF was approximately up to 90 and $119 \mathrm{~nm}$, respectively. Both samples showed that most of the pores were in the range of 2-50 nm, in which significant peaks appeared below $10 \mathrm{~nm}$. According to these results, CF showed an acceptable surface area and average pore diameter, a sign of a good candidate as a drug carrier for controlled drug absorbance and release.
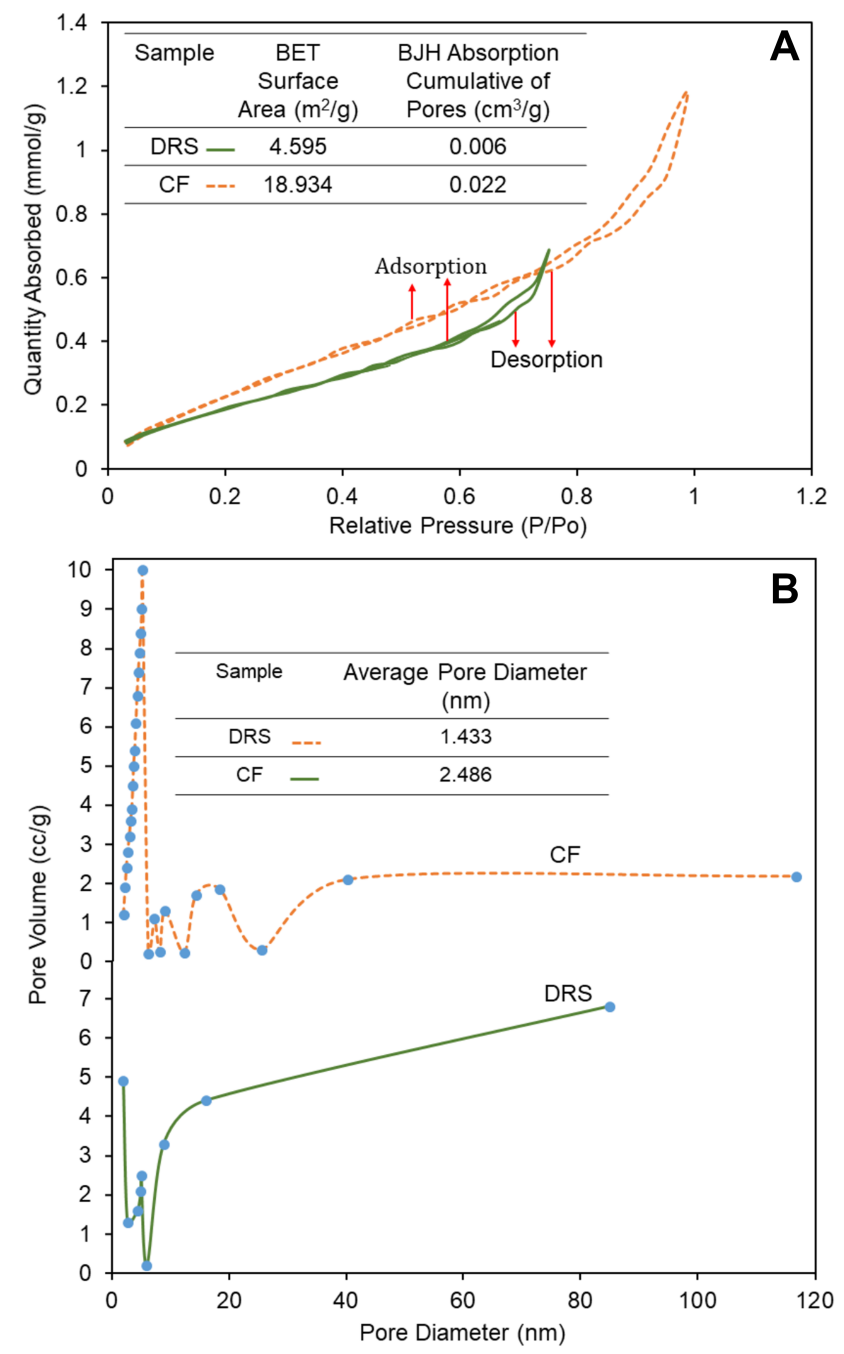

Figure 4 (A) Nitrogen adsorption-desorption isotherms at $77 \mathrm{~K}$ for the selfassembled products from CF and DRS. The inset table lists the Brunauer-EmmettTeller (BET) surface area and Barrett-Joyner-Halenda $(\mathrm{BJH})$ cumulative pore volume calculated from the adsorption branch of each isotherm and (B) average pore diameter of DRS and CF. 


\section{Fourier-Transform Infrared Spectroscopy (FTIR)}

The FTIR spectra of RS, DRS, CF, CF/5-FU, and 5-FU are shown in Figure $5 \mathrm{~A}-\mathrm{E}$, respectively. As can be understood from the figure, $\mathrm{CF}$ was successfully isolated from RS after serial treatments, including de-waxing, delignification, and excretion of silica and hemicellulose. During the bleaching process, the alkali treatment on RS probably caused the formation of $\mathrm{C}-\mathrm{H}$ aromatic hydrogen groups. The peak at $1524 \mathrm{~cm}^{-1}$ (ie, aromatic skeletal vibrations) can be possibly attributed to the presence of pyranose ring skeletal $\mathrm{C}-\mathrm{O}-\mathrm{C}$ bonds of cellulose. Figure 5C presents leaching of the hemicellulose at $1750 \mathrm{~cm}^{-1}$ (carbonyl stretching) and removal of silica (Si-O-Si stretching) at 760 and $491 \mathrm{~cm}^{-1}$. As is seen in Figure 5C, the peaks at 3352, 2891, and $1100 \mathrm{~cm}^{-1}$ could demonstrate the stretching vibrations of $-\mathrm{OH}$ groups, $\mathrm{C}-\mathrm{H}$ stretching, and the cellulose structure, respectively. ${ }^{52}$ In the anomeric region $\left(950-700 \mathrm{~cm}^{-1}\right)$, the minor peak at $887 \mathrm{~cm}^{-1}$ was pronounced for CF (Figure 5C), showing the glycosidic $-\mathrm{C}_{1}-\mathrm{O}-\mathrm{C}_{4}$ deformation property of the $\beta$ glycosidic bond in cellulose. ${ }^{53}$ This possibly showed the successful isolation process of CF. Similar to XRD, FTIR patterns were comparable for cellulose before and after delignification to indicate the high structural stability and no main damage to the cellulose structure.

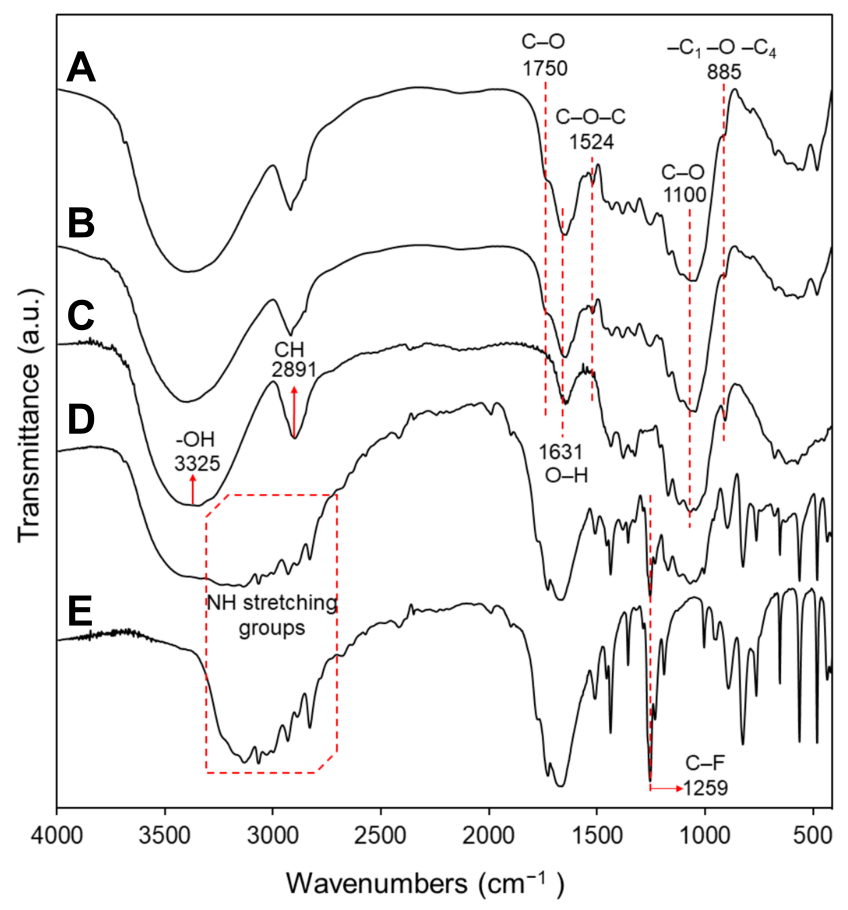

Figure 5 Fourier-transform infrared spectroscopy of (A) RS, (B) DRS (C), CF (D) $\mathrm{CF} / 5-\mathrm{FU}$ and (E) 5-FU.
Figure 5D and E show the FTIR spectrum for $\mathrm{CF} / 5-\mathrm{FU}$ and 5-FU, respectively. Compared to the CF spectrum, the CO stretching group shifted to $1625 \mathrm{~cm}^{-1}$ in the spectrum for $\mathrm{CF} / 5-\mathrm{FU}$. Both $\mathrm{CF} / 5-\mathrm{FU}$ and pure 5-FU displayed similar FTIR patterns showing that the anticancer drug was efficiently conjugated into CF. The spectrum displayed the representative features of drug-loaded $\mathrm{CF}$ of the $\mathrm{OH}$-stretching at $3068 \mathrm{~cm}^{-1}$ and the methylene bands $\mathrm{C}-\mathrm{H}$ at 2829 and $2350 \mathrm{~cm}^{-1}$, while $1984 \mathrm{~cm}^{-1}$ was possibly attributed to the $\mathrm{C}=\mathrm{O}$ stretching vibrations because of the carboxylic groups. The spectrum of 5-FU showed a broadband at $2750-3300 \mathrm{~cm}^{-1}$ attributed to NH stretching groups. This band shifted to $2750-3500 \mathrm{~cm}^{-1}$ in the spectrum of $\mathrm{CF} / 5-\mathrm{FU}$, due to overlapping of the $\mathrm{OH}$ and $\mathrm{NH}$ bonds of 5-FU. ${ }^{39}$ From the spectrum of 5-FU, C-F stretching vibrations were probably at $1271 \mathrm{~cm}^{-1.39}$ This band also shifted to $1279 \mathrm{~cm}^{-1}$ in the spectrum of $\mathrm{CF} / 5-\mathrm{FU}$. Therefore, the main peaks of 5-FU were presented in $\mathrm{CF} / 5$-FU, without any type of incompatibility between the drug and CF.

\section{Zeta Potential}

Figure 6 shows the zeta potential of $\mathrm{CF}$ and $\mathrm{CF} / 5 \mathrm{FU}$. The suspensions of $\mathrm{CF}$ and $\mathrm{CF} / 5-\mathrm{FU}$ had high negative zeta potentials of $-33.61 \mathrm{mV}$ and $-30 \mathrm{mV}$, respectively. These results suggested that $\mathrm{CF}$ has good stability in aqueous solution with or without 5 -FU. ${ }^{54}$ The colloidal suspension with
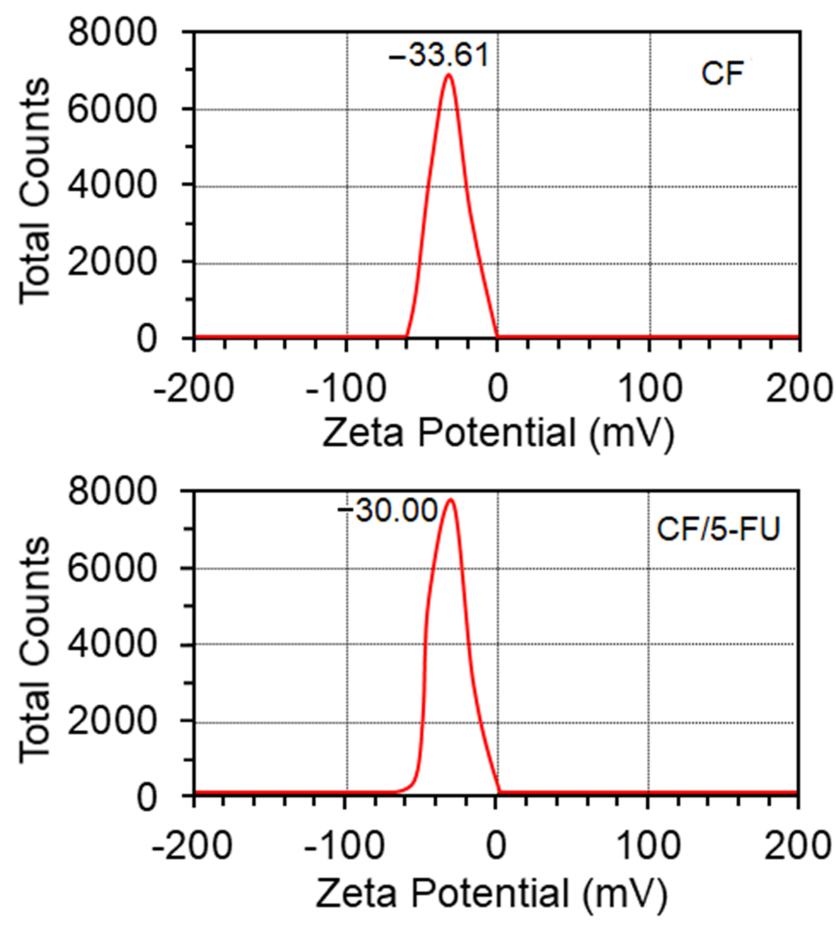

Figure 6 Zeta potential of $\mathrm{CF}$ and $\mathrm{CF} / 5-\mathrm{FU}$. 
good stability resulted from the excellent electrostatic repulsion that occurred among the fibers. The negative charge slightly decreased by adding the drug which covered the CF pores. This showed the successful conjugation between the drug and $\mathrm{CF}$. The $\mathrm{CF}$ with the hydrogen-bonded structure could be adopted by 5-FU in which according to another report, ${ }^{55}$ pure 5-FU showed only one crystal structure which was crystallized through four molecules in the asymmetric unit, and the molecules could accept the hydrogen-bonded feature, while the carboxyl groups in the CF chains possibly caused the presence of hydrogen bonds with the amide groups in the 5-FU molecules to form intermolecular complexes. ${ }^{56}$ Thus, the CF network with a high negative zeta potential conjugated to the anticancer drug 5-FU for potentially an excellent payload and ideal retention in prolonged dosing.

\section{Thermogravimetric Analysis (TGA)}

Figure 7 shows the results of the thermal stability of the $\mathrm{CF}, \mathrm{CF} / 5-\mathrm{FU}$, and 5-FU samples. In the TGA, the initial and the last weight loss are from the primary vaporization and final decomposition, respectively. Though, as the samples were completely dried before analysis, the initial weight loss did not happen which was different from another report. ${ }^{57}$ The main weight loss of 5 -FU was approximately in the range of $260-360^{\circ} \mathrm{C}$ with a residue of $19 \mathrm{wt} . \%$, decreasing to $1.25 \mathrm{wt} . \%$ at $800^{\circ} \mathrm{C}$. The weight loss of $\mathrm{CF} / 5-\mathrm{FU}$ and $\mathrm{CF}$ was approximately in the range of $255-353^{\circ} \mathrm{C}$ and $270-345^{\circ} \mathrm{C}$ with a residue of 33 and 61 wt.\%, respectively, while at $800^{\circ} \mathrm{C}$, the residues were almost unchanged. The residue of $\mathrm{CF}$ was similar to the sorbents from the oil palm empty fruit bunch with considerable inner porosity. ${ }^{58}$ The CF network significantly

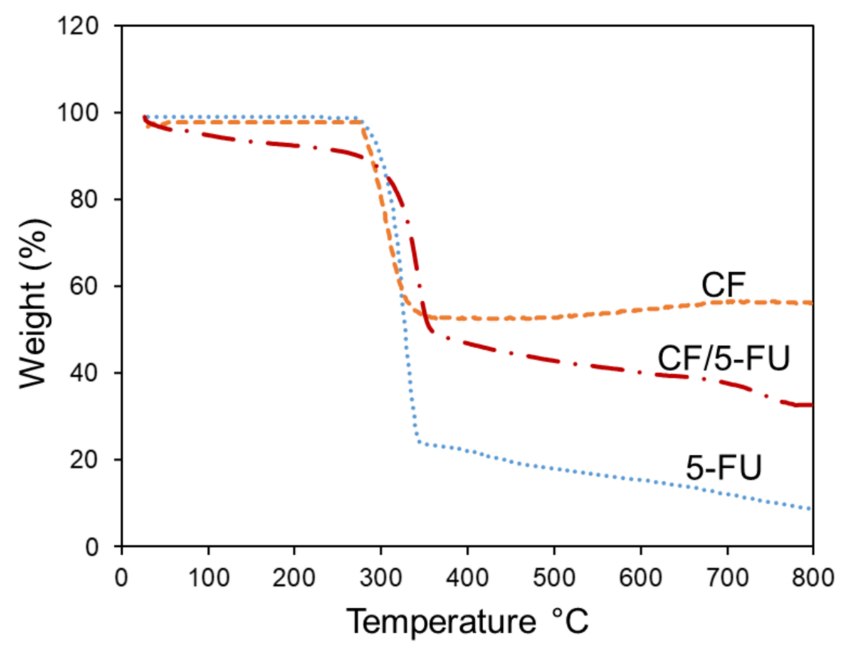

Figure 7 Thermogravimetric analysis of CF, CF/5-FU and 5-FU. increased thermal stability of 5-FU as the main weight loss and the residue increased for $\mathrm{CF} / 5-\mathrm{FU}$. This could show the successful binding between 5-FU and $\mathrm{CF}$ as a drug carrier. From these results, $36.33 \%$ is approximately the lower bound 5-FU percentage in $\mathrm{CF} / 5-\mathrm{FU}$.

\section{Encapsulation Efficiency (EE)\% and Loading Capacity (LC)\%}

Using UV absorbance at various concentrations, measurements for calculating LC and EE were conducted. Based on the UV absorbance and Equation (1), the LC was estimated at $23 \pm 3.2 \%$ to indicate that the $\mathrm{CF} / 5$-FU sample contained almost 23 wt.\% and 77 wt.\% of the drug and CF, respectively. According to the UV absorbance and Equation (2), EE was estimated to be $83 \pm 0.8 \%$. There are several hydroxyl, carboxyl, and carbonyl groups as well as non-polar bonds in the chain structure of the CF network. These functional groups can form hydrogen and/or bipolar bonds with an electronegative atom like fluorine in 5-FU to create van der Waals interactions. This physical bond provided conjugation bonds between the molecular structures of the anticancer drug and CF. It is worth noting that the alkali treatment caused open bonds on the $\mathrm{CF}$ chains in which hydrophilic 5-FU entered into the $\mathrm{CF}$ pores as were swelled in the aqueous solution during the drug loading process. ${ }^{59} \mathrm{CF}$ as the drug carrier matrix with a greater number of $\mathrm{OH}$ groups was effectively bound and released hydrophilic 5-FU by ionic interactions. ${ }^{60}$ Further, the high EE value was due to mechanical entrapment of the drug in the carrier, whereas the CF molecules possibly changed from chains to nanogels in the aqueous solution during magnetic stirring for the drug loading process. ${ }^{61}$ The anticancer drug 5 -FU is a heterocyclic aromatic organic compound with a high solubility and low molecular weight, therefore, it potentially diffused over the open $\mathrm{CF}$ pores increasing its EE value. ${ }^{62}$ Based on the values of $\mathrm{LC} \%$ and $\mathrm{EE} \%$, the $\mathrm{CF}$ network is a good platform for 5-FU loading for use as an improved drug delivery system.

\section{In Vitro Drug Release Studies}

The release of the anticancer drug 5-FU from the CF/5-FU sample is presented in Figure 8. Five different concentrations $(1.0-5.0 \mu \mathrm{g} / \mathrm{mL})$ of the drug were prepared and the UV absorbance was measured at $266 \mathrm{~nm}$ in a glass cuvette of $1.0 \mathrm{~cm}$ width. The drug release behavior of $\mathrm{CF} / 5-\mathrm{FU}$ was studied by conducting in vitro release experiments in media of $\mathrm{pH} 1.2$ and $\mathrm{pH} 7.4$. The time taken to release $46 \%$ and only $21 \%$ of the drug from the carrier was 4 hours at a $\mathrm{pH}$ 7.4 and $\mathrm{pH} 1.2$, respectively. The polymeric structure of $\mathrm{CF}$ 


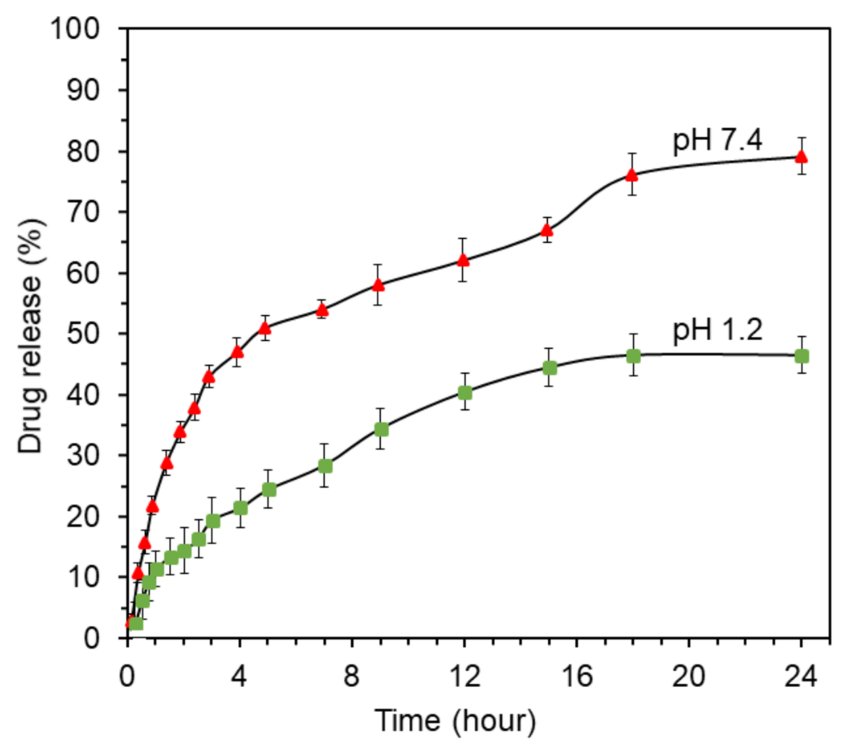

Figure 8 Drug release behavior of 5-FU from $\mathrm{CF}$ in the release media of $\mathrm{pH} 7.4$ and $\mathrm{pH}$ I.2.

with improved roughness was produced via the alkaline treatment and removing the amorphous region. Using $\mathrm{CF}$ in the drug delivery system possibly decreased issues from the pure 5-FU-based treatment, including an unstable biological half-life and immediate release dosage. ${ }^{63}$ From the graph, it is clear that the release (\%) increased with time and gave a maximum $5-\mathrm{FU}$ release of $79 \%$ and $46 \%$ in the release media at $\mathrm{pH} 7.4$ and 1.2 , respectively, within 24 hours. The amount of 5-FU released at $\mathrm{pH} 7.4$ was higher than those delivered at $\mathrm{pH}$ 1.2. Similar results were found from cellulose nanofiber aerogels which served as a Bendamustine hydrochloride carrier, ${ }^{64}$ and a cellulosebased 5-FU carrier, ${ }^{39}$ in which a higher release at $\mathrm{pH} 7.4$ within 24 hours resulted from a greater swelling index of the carriers in media at $\mathrm{pH} \mathrm{7.4.} \mathrm{Therefore,} \mathrm{the} \mathrm{drug} \mathrm{release}$ mechanism was potentially related to the swelling capacity of the CF network and the interaction between the drug and functional groups presented in the drug carrier. As CF can be diminished at acidic $\mathrm{pH}$ values $(\mathrm{pH}$ 1.2), the encapsulated drug can be mostly secured for delivery through the intestine. However, after getting to the intestine, the $\mathrm{pH}$ of the surrounding medium changes to 7.4, therefore, swelling of the material triggers the controlled CF dosage. Similar to a different report, ${ }^{39}$ the controlled dosage was possibly due to the interaction between 5-FU and $-\mathrm{COOH}$ functionalities available in the CF as it declined by an enhanced swelling ratio. Because of the possible swelling, polymer relaxation happens along with drug release from the polymeric system of $\mathrm{CF}$ in controlled behavior. The drug delivery systems with CF cavities may cause an extended-release of the drug. In addition, the interactions between the CF cavity and drug were caused by van der Waals interactions between the hydrophobic moiety of the drug and that of the cavity, which could control the entrapped drug molecule release from the $\mathrm{CF}$ cavity. It is worth mentioning that the drug on the surface of CF was probably released in the first hour, while the breaking of the $\mathrm{CF}$ network caused prolonged drug release. ${ }^{62}$ The release condition in the aqueous solution medium at $37^{\circ} \mathrm{C}$ and the magnetic stirring possibly increased the hydrophilicity of $\mathrm{CF}$ in which the aqueous solution ingressed over the $\mathrm{CF}$ pores and disturbed $\mathrm{CF}$ integrity. $^{62}$ This could minimize the surface area-tovolume ratio of $\mathrm{CF}$ and cause a burst of drug release until there was no drug in the carrier. $\mathrm{CF} / 5-\mathrm{FU}$ did not show a very high prolonged-release behavior probably due to the very low molecular weight and high hydrophilicity of 5-FU. ${ }^{62} \mathrm{CF}$ showed better release behavior than cellulose acetate fibers prepared in a different study, with $95 \%$ of the tetracycline drug release in the first 2 hours. ${ }^{65}$ Also, another survey on gelatin/carboxymethyl cellulose and nanocellulose stated the release of tramadol over 8 and 12 hours, respectively. ${ }^{59}$ The release behavior of $\mathrm{CF} / 5$-FU suggests the potential modification of the proposed CF carrier for the delivery of the anticancer drug in a basic environment for a future clinical setting.

\section{MTS in vitro Cytotoxicity Assays}

The cytotoxic effects of 5-FU, CF, and CF/5-FU against the CCD112 normal colorectal cell line and the HCT116 $\mathrm{CRC}$ cell line are shown in Figure 9A and B, respectively. It can be seen from the figures that $\mathrm{CF}$ alone displayed almost no damage to both normal and cancer cell lines. This may demonstrate the high biocompatibility of the CF network. Results further showed that 5-FU alone mostly killed both cancer and normal cell lines even at its lowest concentration of $7.81 \mu \mathrm{g} / \mathrm{mL}$ after a 72-hour treatment. This proved the drawbacks of using the pure drug in chemotherapy treatment without using a drug carrier system or a drug release controller. The inhibition of $\mathrm{CF} / 5 \mathrm{FU}$ is plotted in CCD112 and HCT116 (Figure 9C). Most importantly, the results showed that the CF/5-FU formulation provided only negligible damage to the normal cell lines, while it displayed great antioxidant and antiproliferation effects against the CRC cell lines. An increasing concentration of $\mathrm{CF} / 5$-FU only slightly improved prohibiting cancer cell line growth. Noticeably, a $250 \mu \mathrm{g} / \mathrm{mL}$ concentration of $\mathrm{CF} / 5-\mathrm{FU}$ had the highest elimination 
(58\%) of cancer cells, although it was only less than $25 \%$ for the normal cells. It is worth mentioning that $\mathrm{CF} / 5-\mathrm{FU}$ still at its minimum concentration of $7.81 \mu \mathrm{g} / \mathrm{mL}$ destroyed more than $41 \%$ of the cancer cells; however, it destroyed only $14 \%$ of the normal cells. As was expected, the cancer cells were gradually killed by an increasing concentration of $\mathrm{CF} / 5-\mathrm{FU}$, albeit, this was moderated for normal cells. It can be understood from Table 1 that the inhibitory concentration (IC50) of CF/5-FU on all tested cell lines was acceptable. Therefore, these results suggest the safety and great potential of using $\mathrm{CF}$ as an anticancer
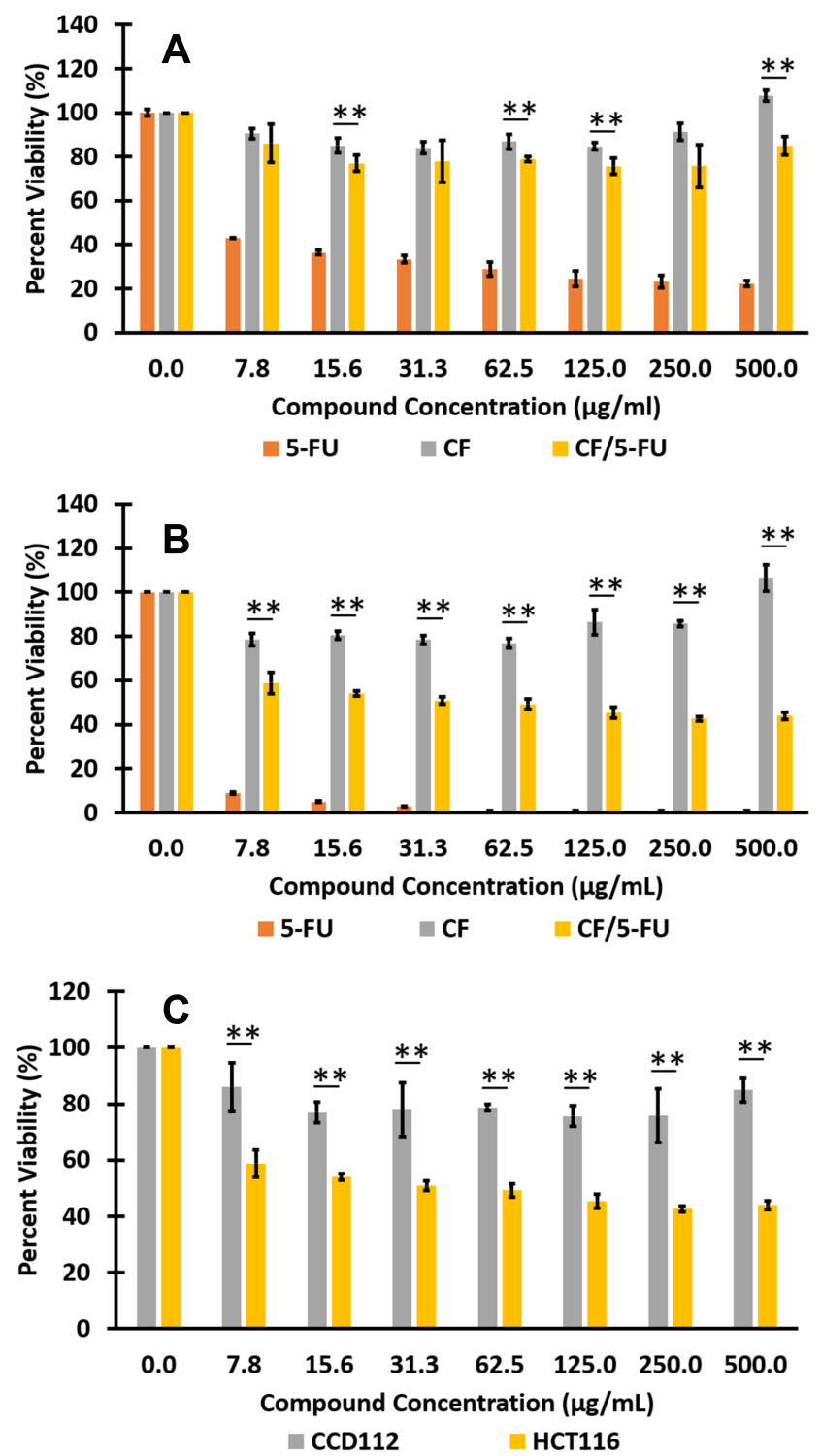

Figure 9 Cytotoxic effects of 5-FU, CF, and CF/5-FU for 72 hours against a (A) CCDII2 normal colorectal cell line, (B) HCTII6 CRC cell line and (C) the inhibition of CF/5FU is plotted in CCDII2 vs HCTII6. Data are expressed as mean + standard deviation for triplicates within an individual experiment. Statistical significance was performed using a Student's $t$ test. $\left({ }^{* *} p<0.05\right)$. drug carrier with high antiproliferation activity against CRC cells and negligible effects toward the colorectal normal healthy cells.

The cytotoxic effects of 5-FU, CF, and CF/5-FU against NP 460 nasopharyngeal normal cell lines and HONE-1 cancer cell lines are shown in Figure 10A and B, respectively. It can be seen from the figures that $\mathrm{CF}$ alone displayed some damage to the normal cells while almost no damage to the cancer cells. Despite that, the pure 5-FU killed almost all of the nasopharyngeal normal and cancer cell lines at the different concentrations, which was a similar effect for the colorectal cells. The CF/5-FU formulation showed a gradual and great antioxidant and antiproliferation effect against the NPC cell lines. An increasing concentration of $\mathrm{CF} / 5$-FU improved cancer cell line death after 72 hours of treatment. Further, $\mathrm{CF} / 5-\mathrm{FU}$ at a $62.5 \mu \mathrm{g} / \mathrm{mL}$ concentration showed a $71 \%$ and $39 \%$ elimination against HONE-1 cancer and NP 460 normal cells, respectively. While, its lowest concentration $(7.8 \mu \mathrm{g} / \mathrm{mL})$ caused a $36 \%$ and only a $6 \%$ killing ratio against cancer and normal cells, respectively. According to the IC50 results from Table 1, the CF/5-FU system displayed major effects against nasopharyngeal normal cell lines. A $500 \mu \mathrm{g} / \mathrm{mL}$ concentration of $\mathrm{CF} / 5-\mathrm{FU}$ showed a greater elimination at $85 \%$ of cancer cells; however, it indicated major damage on the NP 460 normal cell line. The effects from $\mathrm{CF} / 5-\mathrm{FU}$ to nasopharyngeal healthy cells are probably due to the CF properties extracted from RS. It was reported in Europe that wood particles are carcinogens causing NPC for hardwood equipment workers. ${ }^{60,66}$ Some issues that participate in the chemical processing of cellulose products have shown harmful consequences under different exposure ${ }^{67}$ It is worth mentioning that normal cells at confluence reduced their heat-sensitivity 5-6 times than that for the growing situation; however, the cancer cells did not. ${ }^{68}$ Therefore, the normal cells possibly showed a lower temperature (below $37^{\circ} \mathrm{C}$ ) than cancer cells (above $37^{\circ} \mathrm{C}$ ). This slightly increasing temperature of the cancer cells could change the CF network to deswell and deform, thereby,

Table I Inhibitory Concentration (IC50) of 5-FU, CF, and CF/ 5-FU on Tested Cell Lines

\begin{tabular}{|l|l|l|l|}
\hline \multirow{2}{*}{ Cell Line } & \multicolumn{3}{l|}{ Compound $(\boldsymbol{\mu g} / \mathbf{m L})$} \\
\cline { 2 - 4 } & $\mathbf{5 - F U}$ & CF & CF/5-FU \\
\hline HCTII6 & 0.877 & $>500$ & 38.1 \\
CCDII2 & 3.83 & $>500$ & $>500$ \\
HONE-I & 1.32 & $>500$ & 74.16 \\
NP 460 & 6.64 & $>500$ & 16.25 \\
\hline
\end{tabular}



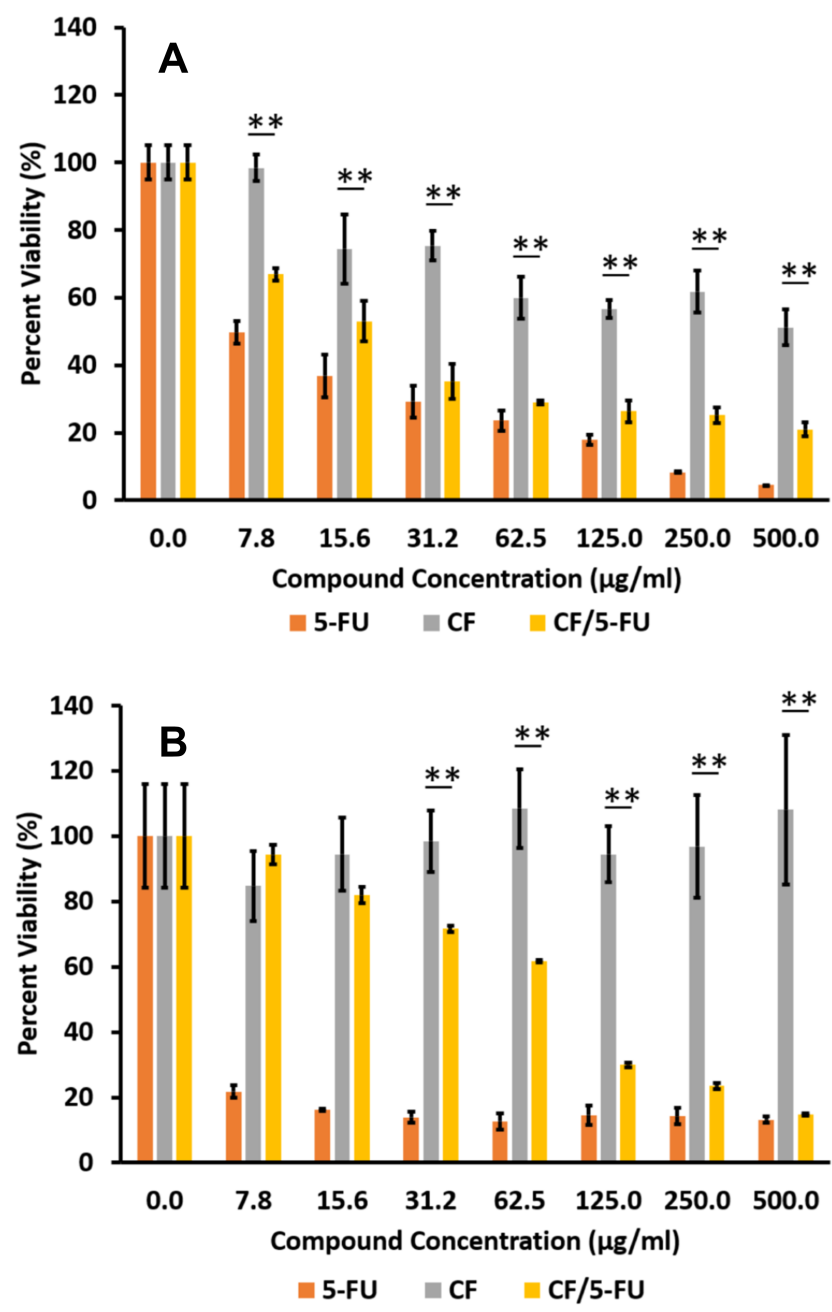

Figure 10 Cytotoxic effects of 5-FU, CF, and CF/5-FU for 72 hours against (A) NP 460 nasopharyngeal normal cell lines and (B) HONE-I cancer cell lines. Data are expressed as mean + standard deviation for triplicates within an individual experiment. Statistical significance was performed using a Student's $t$ test. $\left({ }^{* *} p<0.05\right)$.

triggering a higher release of 5-FU molecules toward the cancer cells than the normal cells. ${ }^{69}$ In this manner, $\mathrm{CF} /$ 5-FU potentially conjugated and improved the selectivity towards the cancer cells to decrease drug leakage from the selected cells for protecting the drug from unwanted degradation and elimination. ${ }^{70}$ Although requiring further investigation and confirmation, especially during in vivo studies, it can be understood from the present results that $\mathrm{CF} / 5 \mathrm{FU}$ can be more suitable in the treatment of CRC than NPC.

\section{Conclusion}

In this study, a facile and eco-friendly alkali treatment was used to isolate $\mathrm{CF}$ from RS waste. The anticancer drug 5-FU was successfully loaded onto the $\mathrm{CF}$ network. The in vitro cytotoxicity assays of the pure 5-FU drug, $\mathrm{CF}$, and $\mathrm{CF} / 5-\mathrm{FU}$ samples were systematically evaluated at eight different concentrations using colorectal and nasopharyngeal healthy and cancerous cell lines in 72 hours of treatment. XRD and FTIR results exhibited the successful bleaching and delignification process on $\mathrm{RS}$ to produce $\mathrm{CF}$ with high purity and crystallinity. Successful treatments were confirmed as CF possessed four times higher surface area and BJH cumulative pore volumes greater than RS. The SEM images illustrated that the $\mathrm{CF}$ was such a rod-shaped polymer. In addition, EDX analysis showed that the drug-loaded sample of $\mathrm{CF} / 5-\mathrm{FU}$ contained the oxygen and carbon elements related to $\mathrm{CF}$, along with an acceptable ratio of fluorine from 5-FU. The FTIR spectrum for CF/5-FU mostly followed that of 5-FU in determining the efficient interaction and conjugation between the drug and the drug carrier. The zeta potentials of $\mathrm{CF}$ and $\mathrm{CF} / 5-\mathrm{FU}$ samples were $-33.61 \mathrm{mV}$ and $-30 \mathrm{mV}$, respectively. TGA data revealed that the CF network significantly increased the thermal stability of 5-FU. Based on the UV-spectroscopy results, the anticancer drug loading onto the $\mathrm{CF}$ carrier system was estimated with an EE of $83 \pm 0.8 \%$. Further, the LC was estimated to be $23 \pm 3.2 \%$, indicating that the CF/5-FU sample contained almost $23 \mathrm{wt} . \%$ and $77 \mathrm{wt} . \%$ of the drug and CF, respectively. Drug release was evaluated in media of different $\mathrm{pH}$ values within 24 hours and gave a maximum 5-FU release of $79 \%$ and $46 \%$ for the release media of $\mathrm{pH} 7.4$ and 1.2, respectively.

Most importantly, in cytotoxicity assays on human colorectal cells after 72 hours of treatment, CF showed high biocompatibility with no harmful effects against CCD112 normal colorectal and HCT116 CRC cells. However, the pure anticancer drug 5-FU critically killed both normal and cancer cells. The drug-loaded sample of CF/5-FU at a $250 \mu \mathrm{g} / \mathrm{mL}$ concentration showed higher growth inhibition (58\%) in the CRC cells compared to the normal cells $(23 \%)$. Even at a concentration of $7.81 \mu \mathrm{g} / \mathrm{mL}, \mathrm{CF} / 5-\mathrm{FU}$ killed more than $41 \%$ of the CRC cells and only $14 \%$ of the normal cells. In cytotoxicity assays on human nasopharyngeal cells after 72 hours of treatment, the NP 460 normal and HONE-1 cancer cell lines were slightly damaged from $\mathrm{CF}$ alone and were mostly killed by the $5-\mathrm{FU}$ pure drug. The $\mathrm{CF} / 5 \mathrm{FU}$ formulation at a $62.5 \mu \mathrm{g} / \mathrm{mL}$ concentration demonstrated antiproliferative effects of $71 \%$ and $39 \%$ against the NPC and the normal cells, respectively. In addition, $\mathrm{CF} / 5-\mathrm{FU}$ at the maximum concentration $(500 \mu \mathrm{g} / \mathrm{mL})$ reached the highest killing ratio $(85 \%)$ on HONE-1 cancer cells, with a noticeable damage on NP 460 normal cell lines. Albeit, $\mathrm{CF} / 5 \mathrm{FU}$ at the lowest concentration $(7.8 \mu \mathrm{g} / \mathrm{mL})$ showed the minimum damage $(6 \%)$ on the normal cells and a $36 \%$ killing ratio against the cancer cells. This research showed that the potential of using the CF network as 
the anticancer drug 5-FU carrier may be more effective in CRC treatment than NPC treatment to decrease the sideeffects of conventional chemotherapy treatment in a green and environmentally safe manner.

\section{Acknowledgments}

The authors wish to acknowledge funding by the Malaysian Ministry of Higher Education under the Tier 1 grants (Grant No. \#20h33 and \#20h55) and express gratitude to the research management center (RMC) of Universiti Teknologi Malaysia and Malaysia-Japan International Institute of Technology for providing an excellent research environment and facilities.

\section{Disclosure}

The authors declare no conflict of interest.

\section{References}

1. Yusefi M, Khalid M, Yasin FM, Abdullah LC, Ketabchi MR, Walvekar R. Performance of cow dung reinforced biodegradable poly (Lactic Acid) biocomposites for structural applications. $J$ Polym Environ. 2018;26(2):474-486. doi:10.1007/s10924-017-0963-z

2. Yusefi M, Khalid M, Yasin FM, Ketabchi MR, Hajalilou A, Abdullah LC. Physico-mechanical properties of poly (lactic acid) biocomposites reinforced with cow dung. Mater Res Express. 2017;4(2):025302. doi:10.1088/2053-1591/aa5cdb

3. Ram H, Dadhwal V, Vashist KK, Kaur H. Grain yield and water use efficiency of wheat (Triticum aestivum L.) in relation to irrigation levels and rice straw mulching in North West India. Agric Water Manag. 2013;128:92-101. doi:10.1016/j.agwat.2013.06.011

4. Ardanuy M, Claramunt J, Toledo Filho RD. Cellulosic fiber reinforced cement-based composites: a review of recent research. Constr Build Mater. 2015;79:115-128. doi:10.1016/j.conbuildmat.2015.01.035

5. Kim JI, Hwang TI, Aguilar LE, Park CH, Kim CS. A controlled design of aligned and random nanofibers for 3D bi-functionalized nerve conduits fabricated via a novel electrospinning set-up. Sci Rep. 2016;6:23761. doi:10.1038/srep2376

6. Gama M, Gatenholm P, Klemm D. Bacterial Nanocellulose: A Sophisticated Multifunctional Material. USA: CRC Press, Taylor \& Francis Group. 2013:263.

7. Cai X, Yang L, Zhang L-M, Wu Q. Synthesis and anaerobic biodegradation of indomethacin-conjugated cellulose ethers used for colon-specific drug delivery. Bioresour Technol. 2009;100 (18):4164-4170. doi:10.1016/j.biortech.2009.04.005

8. Morán JI, Alvarez VA, Cyras VP, Vázquez A. Extraction of cellulose and preparation of nanocellulose from sisal fibers. Cellulose. 2008;15 (1):149-159. doi:10.1007/s10570-007-9145-9

9. Lim SK, Son TW, Lee DW, Park BK, Cho KM. Novel regenerated cellulose fibers from rice straw. J Appl Polym Sci. 2001;82 (7):1705-1708. doi:10.1002/app.2010

10. Agwuncha SC, Anusionwu CG, Owonubi SJ, Sadiku ER, Busuguma UA, Ibrahim ID. Extraction of Cellulose Nanofibers and Their Eco/Friendly Polymer Composites. Cham: Springer. 2019:37-64. doi:10.1007/978-3-030-05399-4_23

11. Bray F, Ferlay J, Soerjomataram I, Siegel RL, Torre LA, Jemal A. Global cancer statistics 2018: GLOBOCAN estimates of incidence and mortality worldwide for 36 cancers in 185 countries. CA Cancer J Clin. 2018;68(6):394-424. doi:10.3322/caac.21492
12. Pang S-W, Awi NJ, Armon S, et al. Current update of laboratory molecular diagnostics advancement in management of colorectal cancer (CRC). Diagnostics. 2020;10(1):9. doi:10.3390/diagnostics10010009

13. Kiesslich R, Burg J, Vieth M, et al. Confocal laser endoscopy for diagnosing intraepithelial neoplasias and colorectal cancer in vivo. Gastroenterology. 2004;127(3):706-713. doi:10.1053/j.gastro.2004.06. 050

14. Lui VWY, Wong EYL, Ho Y, et al. STAT3 activation contributes directly to Epstein-Barr virus-mediated invasiveness of nasopharyngeal cancer cells in vitro. Int $J$ Cancer. 2009;125(8):1884-1893. doi:10.1002/ijc. 24567

15. Yu Q, Zhang N, Jiang Y, et al. RGS17 inhibits tumorigenesis and improves 5-fluorouracil sensitivity in nasopharyngeal carcinoma. Onco Targets Ther. 2018;11:7591. doi:10.2147/OTT.S176002

16. Jahangirian H, Kalantari K, Izadiyan Z, Rafiee-Moghaddam R, Shameli K, Webster TJ. A review of small molecules and drug delivery applications using gold and iron nanoparticles. Int J Nanomedicine. 2019;14:1633-1657. doi:10.2147/IJN.S184723

17. Anirudhan TS, Binusreejayan, Rejeena SR. Synthesis and characterization of chitosan based multilayer and $\mathrm{pH}$ sensitive co-polymeric system for the targeted delivery of 5-fluorouracil, an in vitro study. Int J Polym Mater Pol. 2014;63(11):539-548. doi:10.1080/00914037.2013.854225

18. Jung S, Swamy BY, Moon JB, Kim DH, Chung I. Anti-AIDS active polyrotaxane-AZT conjugates with bioactive bulky stoppers and their nanoparticles. J Polym Sci Pol Chem. 2012;50(23):4895-4901. doi:10.1002/pola. 26317

19. Jahangirian H, Azizi S, Rafiee-Moghaddam R, Baratvand B, Webster TJ. Status of plant protein-based green scaffolds for regenerative medicine applications. Biomolecules. 2019;9(10):619. doi:10.3390/biom9100619

20. Song Z, Chen E, Qian J, et al. Serum chitinase activity prognosticates metastasis of colorectal cancer. BMC Cancer. 2019;19(1):629. doi:10.1186/s12885-019-5834-7

21. Zhang L-K, Du S, Wang X, et al. Bacterial cellulose based composites enhanced transdermal drug targeting for breast cancer treatment. Chem Eng J. 2019;370:749-759. doi:10.1016/j.cej.2019.03.216

22. HPS AK CK, Saurabh A, Adnan A, et al. A review on chitosan-cellulose blends and nanocellulose reinforced chitosan biocomposites: properties and their applications. Carbohydr Polym. 2016;150:216-226. doi:10.1016/j.carbpol.2016.05.028

23. Sharma Monica. Transdermal and intravenous nano drug delivery systems: present and future. In: Applications of Targeted Nano Drugs and Delivery Systems. Elsevier. 2019:499-550. doi:10.1016/ B978-0-12-814029-1.00018-1

24. Jawahar N, Meyyanathan S. Polymeric nanoparticles for drug delivery and targeting: a comprehensive review. Int $J$ Res Health Allied Sci. 2012;1(4):217. doi:10.4103/2278-344X.107832

25. Bae J, Park JW. Preparation of an injectable depot system for long-term delivery of alendronate and evaluation of its anti-osteoporotic effect in an ovariectomized rat model. Int $J$ Pharm. 2015;480(1-2):37-47. doi:10.1016/j.ijpharm.2015.01.020

26. Alasvand N, Urbanska AM, Rahmati M, et al. Therapeutic nanoparticles for targeted delivery of anticancer drugs. In: Multifunctional Systems for Combined Delivery, Biosensing and Diagnostics. Elsevier. 2017:245-259. doi:10.1016/B978-0-323-52725-5.00013-7

27. Li L, Ten Hagen TL, Bolkestein M, et al. Improved intratumoral nanoparticle extravasation and penetration by mild hyperthermia. J Control Release. 2013;167(2):130-137. doi:10.1016/j.jconrel.2013.01.026

28. Matsumura Y, Maeda H. A new concept for macromolecular therapeutics in cancer chemotherapy: mechanism of tumoritropic accumulation of proteins and the antitumor agent smancs. Cancer Res. 1986;46(12 Part 1):6387-6392.

29. Anirudhan TS, Christa J. Multi-polysaccharide based stimuli responsive polymeric network for the in vitro release of 5-fluorouracil and levamisole hydrochloride. New J Chem. 2017;41(20):11979-11990. doi:10.1039/C7NJ01745F 
30. Meyerhardt JA, Li L, Sanoff HK, Carpenter W IV, Schrag D Effectiveness of bevacizumab with first-line combination chemotherapy for Medicare patients with stage IV colorectal cancer. $J$ Clin Oncol. 2012;30(6):608. doi:10.1200/JCO.2011.38.9650

31. Niedzwiecki D, Hasson RM, Lenz HJ, et al. A study of thymidylate synthase expression as a biomarker for resectable colon cancer: alliance (cancer and leukemia group B) 9581 and 89803 . Oncologist. 2017;22(1):107. doi:10.1634/theoncologist.2016-0215

32. Fearnhead H, Gul S. Using clinical drug resistance to kill cancer cells. Drug Target Rev. 2017;2(22):12-14.

33. Glimelius B, Graf W, Hoffman K, Påhlman L, Sjödén P-O WA. General condition of asymptomatic patients with advanced colorectal cancer receiving palliative chemotherapy: a longitudinal study. Acta Oncol. 1992;31(6):645-651. doi:10.3109/02841869209083847

34. Österlund P, Ruotsalainen T, Peuhkuri K, et al. Lactose intolerance associated with adjuvant 5 -fluorouracil-based chemotherapy for colorectal cancer. Clin Gastroenterol Hepatol. 2004;2(8):696-703. doi:10.1016/S1542-3565(04)00293-9

35. Srivastava S, Mohammad S, Gupta S, et al. Chemoprotective effect of nanocurcumin on 5-fluorouracil-induced-toxicity toward oral cancer treatment. Natl J Maxillofac Surg. 2018;9(2):160. doi:10.4103/ njms.NJMS 27 18

36. Rokhade AP, Shelke NB, Patil SA, Aminabhavi TM. Novel hydrogel microspheres of chitosan and pluronic F-127 for controlled release of 5-fluorouracil. J Microencapsul. 2007;24(3):274-288. doi:10.1080/ 02652040701281365

37. Zheng D, Deng Y, Xia Y, et al. Fabrication and performance of a spherical cellulose nanocrystal-based hydrophobic drug delivery vehicle using rubber wood. Bioresources. 2019;14(4):7763-7774. doi:10.15376/biores.14.4.7763-7774

38. Abe K, Yano H. Comparison of the characteristics of cellulose microfibril aggregates of wood, rice straw and potato tuber. Cellulose. 2009;16(6):1017-1023. doi:10.1007/s10570-009-9334-9

39. Anirudhan TS, Nima J, Divya PL. Synthesis, characterization and in vitro cytotoxicity analysis of a novel cellulose based drug carrier for the controlled delivery of 5-fluorouracil, an anticancer drug. Int J Polym Mater. 2015;355:64-73. doi:10.1080/00914037.20 13.854225

40. abm. Immortalized Human Nasopharyngeal Epithelial Cells (NP460) - hTERT; 2019. Available from: https://www.abmgood. com/Immortalized-Human-Nasopharyngeal-Epithelial-Cells -(NP460)-hTERT-T0635.html. Accessed July 18, 2020.

41. Glaser R, Zhang H-Y, Yao K, et al. Two epithelial tumor cell lines (HNE-1 and HONE-1) latently infected with Epstein-Barr virus that were derived from nasopharyngeal carcinomas. Proc Natl Acad Sci. 1989;86(23):9524-9528. doi:10.1073/pnas.86.23.9524

42. Chan SYY, Choy KW, Tsao SW, et al. Authentication of nasopharyngeal carcinoma tumor lines. Int J Cancer. 2008;122(9):2169-2171. doi:10.1002/ijc. 23374

43. Ismail NA, Shameli K, Wong MM-T, Teow S-Y, Chew J, Sukri SNAM. Antibacterial and cytotoxic effect of honey mediated copper nanoparticles synthesized using ultrasonic assistance. Mater Sci Eng C. 2019;104:109899. doi:10.1016/j.msec.2019.109899

44. Sukri SNAM, Shameli K, Wong MM-T, Teow S-Y, Chew J, Ismail NA. Cytotoxicity and antibacterial activities of plant-mediated synthesized zinc oxide $(\mathrm{ZnO})$ nanoparticles using Punica granatum (pomegranate) fruit peels extract. $J$ Mol Struct. 2019;1189:57-65. doi:10.1016/j.molstruc.2019.04.026

45. Yusefi M, Shameli K, Ali RR, Pang S-W, Teow S-Y. Evaluating anticancer activity of plant-mediated synthesized iron oxide nanoparticles using Punica Granatum fruit peel extract. J Mol Struct. 2020;1204:127539. doi:10.1016/j.molstruc.2019.127539

46. Hessien M, Rashad M, Zaky R, Abdel-Aal E, El-Barawy K. Controlling the synthesis conditions for silica nanosphere from semi-burned rice straw. Mater Sci Eng B. 2009;162(1):14-21. doi:10.1016/j.mseb.2009.01.029
47. Lu P, Hsieh Y-L. Preparation and characterization of cellulose nanocrystals from rice straw. Carbohydr Polym. 2012;87(1):564-573. doi:10.1016/j.carbpol.2011.08.022

48. Wu R-L, Wang X-L, Wang Y-Z, Bian X-C, Li F. Cellulose/soy protein isolate blend films prepared via room-temperature ionic liquid. Ind Eng Chem Res. 2009;48(15):7132-7136. doi:10.1021/ ie 9001052

49. Chen W, Yu H, Liu Y, Chen P, Zhang M, Hai Y. Individualization of cellulose nanofibers from wood using high-intensity ultrasonication combined with chemical pretreatments. Carbohydr Polym. 2011;83 (4):1804-1811. doi:10.1016/j.carbpol.2010.10.040

50. Basta A, Fierro V, El-Saied H, Celzard A. 2-Steps KOH activation of rice straw: an efficient method for preparing high-performance activated carbons. Bioresour Technol. 2009;100(17):3941-3947. doi:10.1016/j.biortech.2009.02.028

51. Nandiyanto A, Rahman T, Fadhlulloh M, Abdullah A, Hamidah I, Mulyanti B. Synthesis of silica particles from rice straw waste using a simple extraction method. IOP Conf Ser Mater Sci Eng. 2016;128:012040. doi:10.1088/1757-899X/128/1/012040

52. Chen X, Yu J, Zhang Z, Lu C. Study on structure and thermal stability properties of cellulose fibers from rice straw. Carbohydr Polym. 2011;85(1):245-250. doi:10.1016/j.carbpol.2011.02.022

53. Jiang F, Hsieh Y-L. Chemically and mechanically isolated nanocellulose and their self-assembled structures. Carbohydr Polym. 2013;95 (1):32-40. doi:10.1016/j.carbpol.2013.02.022

54. de Oliveira JP, Bruni GP, Lima KO, et al. Cellulose fibers extracted from rice and oat husks and their application in hydrogel. Food Chem. 2017;221:153-160. doi:10.1016/j.foodchem.2016.10.048

55. Hulme AT, Price SL, Tocher DA. A new polymorph of 5-fluorouracil found following computational crystal structure predictions. $J \mathrm{Am}$ Chem Soc. 2005;127(4):1116-1117. doi:10.1021/ja044336a

56. Li Q, Liu C-G, Huang Z-H, Xue -F-F. Preparation and characterization of nanoparticles based on hydrophobic alginate derivative as carriers for sustained release of vitamin D3. J Agric Food Chem. 2011;59(5):1962-1967. doi:10.1021/jf1020347

57. Zainuddin N, Ahmad I, Kargarzadeh H, Ramli S. Hydrophobic kenaf nanocrystalline cellulose for the binding of curcumin. Carbohydr Polym. 2017;163:261-269. doi:10.1016/j.carbpol.2017.01.036

58. Daneshfozoun S, Abdullah M, Abdullah B. Preparation and characterization of magnetic biosorbent based on oil palm empty fruit bunch fibers, cellulose and Ceiba pentandra for heavy metal ions removal. Ind Crops Prod. 2017;105:93-103. doi:10.1016/j.indcrop.2017.05.011

59. Kadry G. Comparison between gelatin/carboxymethyl cellulose and gelatin/carboxymethyl nanocellulose in tramadol drug loaded capsule. Heliyon. 2019;5(9):e02404. doi:10.1016/j.heliyon.2019. e02404

60. Seabra AB, Bernardes JS, Fávaro WJ, Paula AJ, Durán N. Cellulose nanocrystals as carriers in medicine and their toxicities: a review. Carbohydr Polym. 2018;181:514-527. doi:10.1016/j.carbpol.20 17.12.014

61. Zhu K, Ye T, Liu J, et al. Nanogels fabricated by lysozyme and sodium carboxymethyl cellulose for 5-fluorouracil controlled release. Int $J$ Pharm. 2013;441(1-2):721-727. doi:10.1016/j. ijpharm.2012.10.022

62. Illangakoon UE, Yu D-G, Ahmad BS, Chatterton NP, Williams GR. 5-Fluorouracil loaded Eudragit fibers prepared by electrospinning. Int J Pharm. 2015;495(2):895-902. doi:10.1016/j.ijpharm.2015.09. 044

63. Radu IC, Hudita A, Zaharia C, et al. Poly (3-hydroxybutyrate-CO -3-hydroxyvalerate) PHBHV biocompatible nanocarriers for 5-FU delivery targeting colorectal cancer. Drug Deliv. 2019;26 (1):318-327. doi:10.1080/10717544.2019.1582729

64. Bhandari J, Mishra H, Mishra PK, Wimmer R, Ahmad FJ, Talegaonkar S. Cellulose nanofiber aerogel as a promising biomaterial for customized oral drug delivery. Int $J$ Nanomedicine. 2017;12:2021. doi:10.2147/IJN.S124318 
65. Pragati S, Ashok S, Kuldeep S. Recent advances in periodontal drug delivery systems. Int J Drug Deliv. 2009;1(1). doi:10.5138/ijdd.20 09.0975.0215.01001

66. Cancer IAfRo. IARC Monographs on the Evaluation of Carcinogenic Risk of Chemicals to Man; 1972:1

67. Roman M. Toxicity of cellulose nanocrystals: a review. Ind Biotechnol. 2015;11(1):25-33. doi:10.1089/ind.2014.0024

68. Watanabe M, Suzuki K. Heat sensitivity of human cancer cells and abnormal expression of heat shock protein 70. Gan No Rinsho. 1989;35(13):1512-1516.
69. Norouzi M, Nazari B, Miller DW. Electrospun-based systems in cancer therapy. In: Electrospun Materials for Tissue Engineering and Biomedical Applications. Elsevier. 2017:337-356. doi:10.1016/ B978-0-08-101022-8.00013-2

70. Banerjee A, Pathak S, Subramanium VD, Dharanivasan G, Murugesan R, Verma RS. Strategies for targeted drug delivery in treatment of colon cancer: current trends and future perspectives. Drug Discov Today. 2017;22(8):1224-1232. doi:10.1016/j.drudis.20 17.05 .006

\section{Publish your work in this journal}

The International Journal of Nanomedicine is an international, peerreviewed journal focusing on the application of nanotechnology in diagnostics, therapeutics, and drug delivery systems throughout the biomedical field. This journal is indexed on PubMed Central, MedLine, CAS, SciSearch ${ }^{\mathbb{R}}$, Current Contents ${ }^{\mathbb{R}} /$ Clinical Medicine, $^{-}$
Journal Citation Reports/Science Edition, EMBase, Scopus and the Elsevier Bibliographic databases. The manuscript management system is completely online and includes a very quick and fair peer-review system, which is all easy to use. Visit http://www.dovepress.com/ testimonials.php to read real quotes from published authors. 